\title{
1 Focal seizures are organized by feedback between neural activity and ion concentration changes
}

\section{Damiano Gentiletti, ${ }^{1}$ Marco de Curtis, ${ }^{2}$ Vadym Gnatkovsky, ${ }^{2,3}$ and Piotr Suffezynski, ${ }^{1 *}$}

Author affiliations:

61 Department of Biomedical Physics, Faculty of Physics, University of Warsaw, 02-093

7 Warsaw, Poland

$11{ }^{*}$ Corresponding author: suffa@fuw.edu.pl

\section{Abstract}

14 Human and animal EEG data demonstrate that focal seizures start with low-voltage fast activity,

15 evolve into rhythmic burst discharges and are followed by a period of suppressed background 16 activity. This suggests that processes with dynamics in the range of tens of seconds govern focal 17 seizure evolution. We investigate the processes associated with seizure dynamics by 18 complementing the Hodgkin-Huxley mathematical model with the physical laws that dictate ion 19 movement and maintain ionic gradients. We show that the disturbance of $\mathrm{K}^{+}$and $\mathrm{Cl}^{-}$homeostasis 20 by the fast discharge of inhibitory interneurons is sufficient to initiate seizures, which are 21 maintained by positive feedback between ion concentration changes and neuronal activity. 22 Gradual $\mathrm{Na}^{+}$accumulation increases the rate of the $\mathrm{Na}^{+} / \mathrm{K}^{+}$-pump, creating negative feedback 23 which slows down and terminates ictal discharges and contributes to the postictal state. Our 24 results emphasize ionic dynamics as elementary processes behind seizure generation and indicate targets for new therapeutic strategies. 


\section{Introduction}

27 Focal seizure patterns recorded with intracranial and intracerebral electrodes in patients submitted to presurgical evaluation often consist of distinct phases (Franaszczuk et al., 1998; Spencer et al., 1992; Velascol et al., 2000). A frequently observed onset pattern in patients with temporal lobe epilepsy (TLE) is characterized by low-voltage fast (LVF) activity in the gamma range (30-80 Hz) (Avoli et al., 2016; de Curtis \& Gnatkovsky, 2009; Lagarde et al., 2019; Perucca et al., 2014). LVF seizure onset is followed by the recruitment of irregular spiking behavior which evolves into periodic burst discharges that gradually decrease in frequency and suddenly cease. Seizures are often followed by a period of reduced EEG amplitude known as postictal EEG suppression. The traditional view on epileptic seizures is that they result from an imbalance of synaptic excitation and inhibition (Bradford, 1995; Bragin et al., 2009). It is unclear how this concept may account for the electroencephalographic complexity of TLE seizures and their characteristic progression from one phase to the next. The findings of several studies have not confirmed the role of synaptic interaction in seizure generation or progression. It has been shown that blocking synaptic transmission via a low $\mathrm{Ca}^{2+}$ solution led to the development of synchronized seizure-like events (SLE) in hippocampal CA1 slices (Jefferys \& Haas, 1982; Yaari et al., 1983) and in the intact hippocampus (Feng \& Durand, 2003). Moreover, the synchronized epileptiform activity can be recorded across two hippocampal regions separated by a mechanical lesion, without the involvement of electrochemical synaptic communication (Lian et al., 2001). Finally, in photosensitive baboons, light-induced neocortical seizure discharges were accompanied by depletion of extracellular $\mathrm{Ca}^{2+}$ to levels incompatible with the chemical synaptic transmission (Pumain et al., 1985). Additionally, a paradoxical increase in inhibitory cell firing and a decrease in pyramidal cell activity at seizure onset was documented in in vitro rodent slices (Derchansky et al., 2008; Fujiwara-Tsukamoto et al., 2007; Lévesque et al., 2016; Lillis et al., 2012; Ziburkus et al., 2006), in the in vitro whole guinea pig brain (Gnatkovsky et al., 2008; Uva et al., 2015), and in human and animal in vivo recordings (Elahian et al., 2018; Grasse et al., 2013; Miri et al., 2018; Toyoda et al., 2015; Truccolo et al., 2011).

53 The above-mentioned studies suggest that processes at the network level related to changes in synaptic gains cannot be the sole mechanisms that control seizure generation and progression, and that other factors must be involved in the process of ictogenesis. synchronization (Blauwblomme et al., 2014; de Curtis et al., 2018; Jefferys et al., 2012; 
Raimondo et al., 2015), the specific mechanisms responsible for seizure induction, evolution and

59 termination remain unclear. In the present study, we investigated the possible mechanisms of the

60 LVF seizure pattern using a realistic computational model of the hippocampal network that

61 included activity-dependent ion concentration changes. We based our simulations on the data

62 recorded in the in vitro isolated guinea pig brain preparation, which is an animal model of human

63 temporal lobe seizures (de Curtis et al., 2006; de Curtis \& Gnatkovsky, 2009). We used these

64 experimental recordings to guide our in silico study due to the availability of data at the network,

65 cellular and ionic levels. A computer model was used to demonstrate that seizures initiated via

66 increased interneuron discharges, evolved, and terminated autonomously due to activity-

67 dependent ion concentration shifts and homeostatic mechanisms that worked continuously to

68 restore physiological transmembrane ion levels. Our modelling results suggest a link between

69 the seizure termination mechanism and postictal suppression state and predict a specific scaling

70 law of inter-bursting intervals observed at the end of seizures, which was validated

71 experimentally.

\section{Results}

73 The model consisted of five cells, four pyramidal neurons (PY) and a fast-spiking inhibitory

74 interneuron (IN), arranged as a chain structure (Fig. 1). The ionic dynamics of $\mathrm{K}^{+}, \mathrm{Na}^{+}, \mathrm{Ca}^{2+}$ and

$75 \mathrm{Cl}^{-}$were incorporated and activity-dependent changes in their concentrations were computed.

76 Concentration changes in each extracellular or intracellular compartment were dependent on

77 several mechanisms such as active and passive membrane currents, inhibitory synaptic GABAa

78 currents, $\mathrm{Na}^{+} / \mathrm{K}^{+}$-pump, $\mathrm{KCC} 2$ cotransporter, glial $\mathrm{K}^{+}$buffer, $\mathrm{Ca}^{2+}$ pump and buffer, radial

79 diffusion, longitudinal diffusion and volume changes. Additionally, we included impermeant

80 anions $\left(\mathrm{A}^{-}\right)$with concentration dependent volume changes and bicarbonate ions $\left(\mathrm{HCO}_{3}{ }^{-}\right)$that

81 contributed to GABAa currents. 


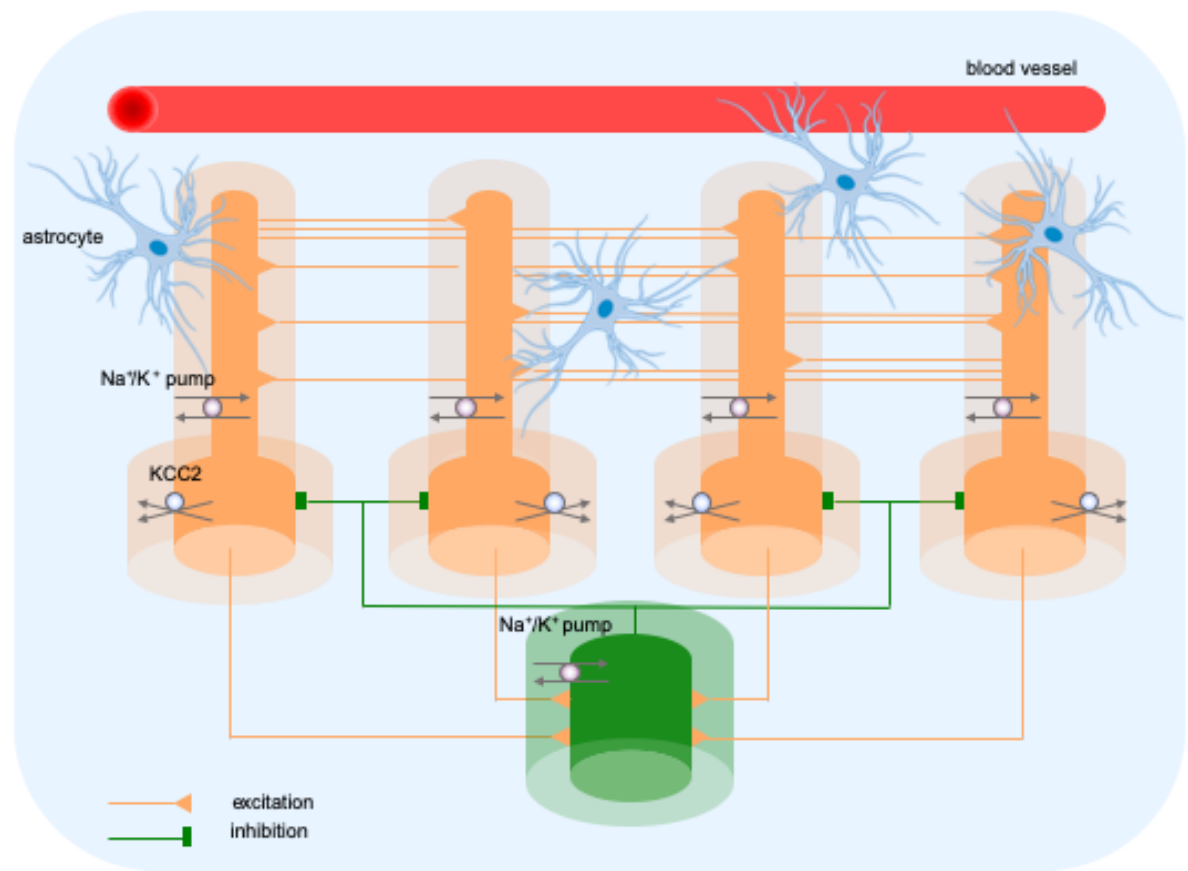

Figure 1. Model diagram. The model consisted of four pyramidal cells (orange) and an interneuron (green) linked by excitatory (AMPA) and inhibitory (GABAa) synaptic connections. Each cellular compartment was surrounded by an interstitial compartment. The interstitial space was enclosed in a common bath (blue) which represented the surrounding tissue and vasculature not included in the model. The model included variable intracellular and extracellular ion concentrations computed according to ionic currents flowing across neuronal membranes, longitudinal diffusion between the dendritic and somatic compartments, radial diffusion between neighboring interstitial compartments and diffusion to/from the bath. Additionally, the model included ionic regulation mechanisms: a $\mathrm{Na}^{+} / \mathrm{K}^{+}$-pump, a $\mathrm{KCC} 2$ cotransporter and $\mathrm{K}^{+}$buffering by astrocytes.

\section{Three phases of an LVF onset SLE}

A simulated SLE emerging from normal background activity is shown in Fig. 2. To test the hypothesis that the onset of focal seizures is associated with an increased discharge of IN (de

96 Curtis \& Avoli, 2016), we applied a depolarizing current (Fig. 2C, yellow trace) to the IN at second 60. Strong firing (initial rate of $270 \mathrm{~Hz}$ ) of the IN (Fig. 2C) led to small amplitude fast activity in the LFP signal (Fig. 2A between the 60 and 65-second timestamps) associated with the onset of the simulated SLE. After approximately 10 seconds, the PY cells began to generate

100 a strong tonic discharge, resulting in an irregular LFP spiking signal with increased amplitude

101 typically associated with the SLE tonic phase (Fig. 2B; 65-80 seconds). Approximately 15-20 
seconds after the onset of the SLE, the cellular firing pattern of PY cells switched from tonic to

103 bursting discharge, leading to LFP oscillations which corresponded to the bursting phase (Fig.

$1042 \mathrm{~A}$, after 80 seconds). As the SLE progressed, the burst rate gradually decreased and ictal

105 discharges spontaneously terminated. Postictally, the SLE was followed by a period of silence

106 for approximately 30 seconds which was visible in the LFP signal and in the PY and IN traces

107 (Fig. 2A-C). After the postictal depression, the background firing reappeared and gradually

108 returned to a baseline level. The SLE discharges were accompanied by significant changes in the

109 intracellular and extracellular ionic concentrations. At the onset of the seizure, extracellular

110 potassium concentration $\left(\left[\mathrm{K}^{+}\right]_{\mathrm{o}}\right)$ increased sharply in the somatic compartment, remained

111 elevated throughout the SLE and slightly decreased toward the end of the episode (Fig. 2D).

112 Intracellular sodium concentration $\left(\left[\mathrm{Na}^{+}\right]_{\mathrm{i}}\right)$ steadily increased during the bursting phase in both

113 somatic and dendritic compartments and reached a plateau around the offset of the SLE (Fig.

$1142 \mathrm{E})$. Intracellular chloride concentration $\left(\left[\mathrm{Cl}^{-}\right]_{\mathrm{i}}\right)$ exhibited a gradual increase from the beginning

115 of the SLE and was highest at the end of the paroxysmal firing (Fig. 2F).

A

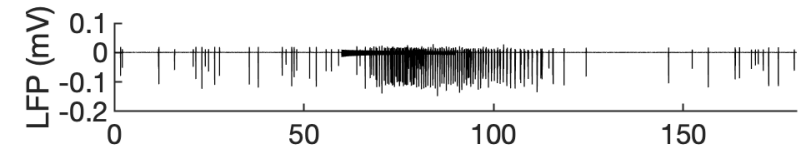

B

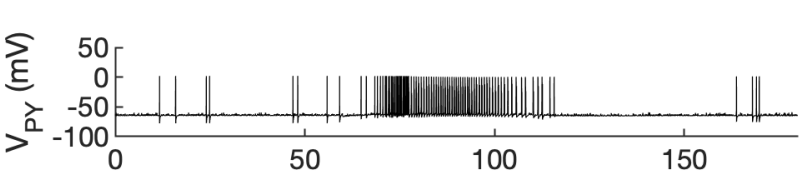

C

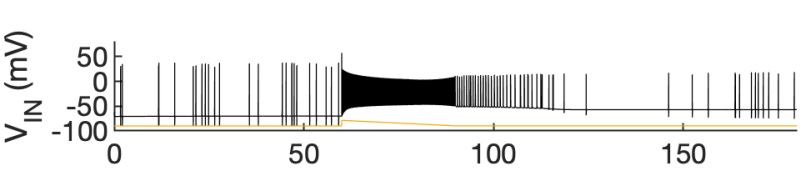

D

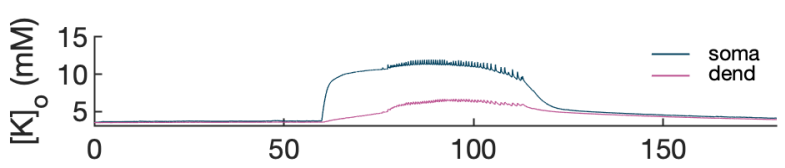

E

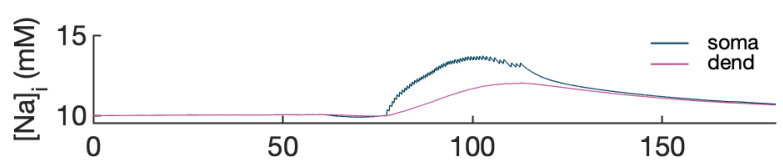

$\mathbf{F}$

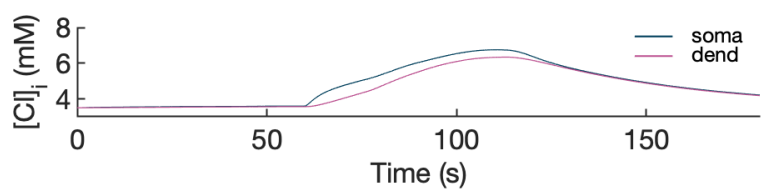

117 Figure 2. Model behavior during an SLE. (A) Local field potential (LFP) signal. (B)

118 Pyramidal cell (PY) membrane potential. (C) Interneuron (IN) membrane potential. (D) 
119 Extracellular potassium concentration. (E) Intracellular sodium concentration. (F) Intracellular

120 chloride concentration. In the interictal phase (0-60 seconds), the model generated irregular

121 background firing and the ion concentrations were at their resting values (A-F). The current

122 injected into the interneuron at second 60 (C, yellow) triggered fast IN spiking (C, black) which

123 also manifested as low voltage fast activity in the LFP signal (A). Approximately 10 seconds

124 after the initiation of the SLE, PY cells initiated tonic firing that subsequently shifted to bursting

125 (B). The behavior of the PY cells was reflected in the LFP trace which showed irregular activity

126 and synchronized bursting (A). The SLE terminated at approximately second 120 and was

127 followed by a period of reduced excitability (A-C). The cellular activity was accompanied by

128 significant ion concentration shifts. Extracellular potassium in the somatic compartment

129 increased sharply and remained elevated throughout the SLE (D, dark blue). The $\left[\mathrm{K}^{+}\right]_{\mathrm{o}}$ increase

130 in the dendritic compartment was slower and less pronounced (D, violet). The intracellular

131 sodium increased gradually toward a plateau (E). The intracellular chloride accumulated steadily

132 throughout the SLE (F).

A comparison of the simulation results with the available experimental data is shown in

134 Fig. 3. In the isolated guinea pig brain, the SLE activity with an LVF onset pattern (Fig. 3A, top

135 trace) was induced by the arterial application of bicuculine. The transition from preictal to ictal

136 state which occurred at approximately second 10 was associated with a strong discharge of fast-

137 spiking interneurons (Fig. 3A, third trace) and transient silencing of the PY cells (Fig. 3A, second

138 trace). The strong preictal firing of the PY cells was artificially triggered by the injection of a

139 steady depolarizing current via the intracellular recording electrode to analyze the intracellular

140 firing correlates during the SLE (Gnatkovsky et al., 2008). Within a few seconds from the

141 initiation of the sustained interneuron discharge, the principal PY cells were recruited first into

142 tonic firing and subsequently into bursting discharges which were visible in the PY membrane

143 potential and LFP signals. $\left[\mathrm{K}^{+}\right]_{\mathrm{o}}$ sharply increased at the onset of the SLE and remained elevated

144 afterward (Fig. 3A, bottom trace). The in silico results (shown for comparison in the same 145 timescale in Fig. 3B) replicated the experimental data in many respects including LFP signal

146 characteristics, cellular firing pattern and $\left[\mathrm{K}^{+}\right]_{\mathrm{o}}$ time course. 
A
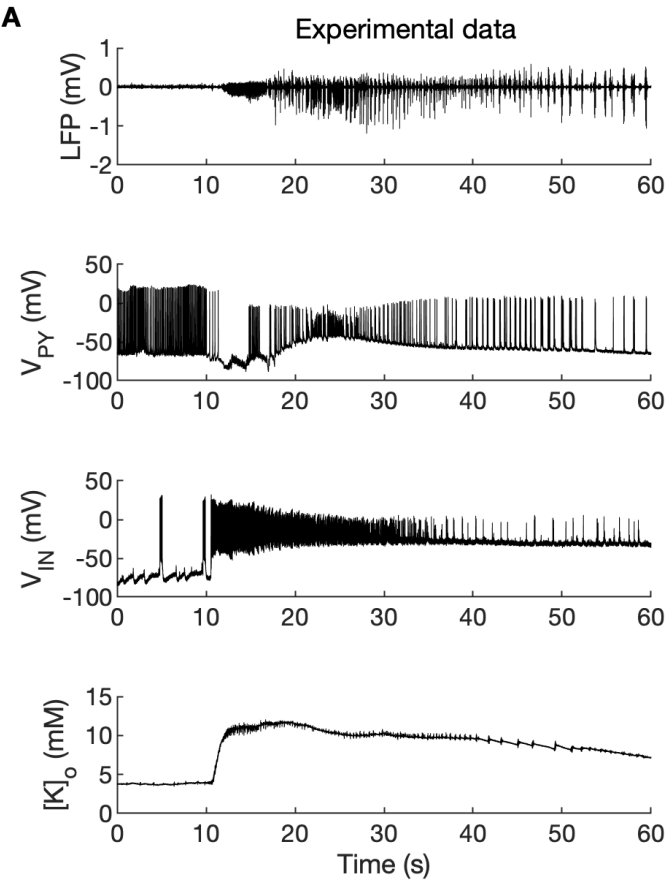

B
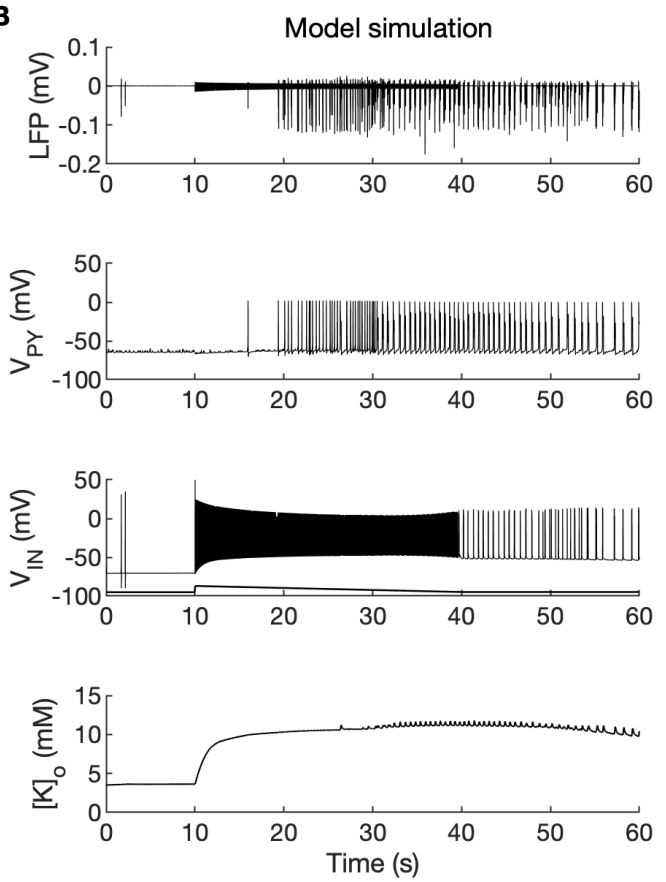

Figure 3. A comparison between the experimental data and the model simulation. (A)

149 Experimental recordings of a seizure-like event (SLE) in the in vitro isolated whole guinea pig

150 brain preparation (de Curtis et al., 2006; Gnatkovsky et al., 2008; Uva et al., 2015). From top to

151 bottom: LFP signal, intracellular recording of pyramidal cell (PY) and interneuron (IN),

152 extracellular potassium. The onset of the SLE was associated with increased IN firing, silencing

153 PY and low-voltage fast (LVF) activity in the LFP signal. Approximately 10 seconds after the

154 onset of the SLE, the PY exhibited a tonic and then burst firing behavior. The extracellular

155 potassium increased up to approximately $10 \mathrm{mM}$ at the onset of the SLE and remained elevated

156 afterward. (B) The activity patterns in the LFP signal, pyramidal cells, interneuron and $\left[\mathrm{K}^{+}\right]_{\mathrm{o}}$

157 were reproduced accurately by the model except for preictal firing of the PY cell seen in A,

158 which was artificially depolarized above resting membrane potential to highlight the role of the

159 inhibitory interneurons during the SLE (Gnatkovsky et al., 2008).

In the simulations, the excitatory and inhibitory synaptic conductances were "clamped"

161 throughout the entire simulation period, hence, they could not contribute to the progression from

162 one phase to another. Conversely, variations in ion concentrations were expected to affect

163 neuronal excitability. For example, an increase in $\left[\mathrm{K}^{+}\right]_{\mathrm{o}}$ reduces the driving force of $\mathrm{K}^{+}$currents

164 responsible for hyperpolarized resting membrane potential and spike repolarization. $\left[\mathrm{Na}^{+}\right]_{\mathrm{i}}$ and

$165\left[\mathrm{~K}^{+}\right]_{\mathrm{o}}$ affect the rate of the $\mathrm{Na}^{+} / \mathrm{K}^{+}$-pump that transports three $\mathrm{Na}^{+}$ions out of the cell for every

166 two $\mathrm{K}^{+}$ions pumped into the cell, thus producing an outward current. Accumulation of $\left[\mathrm{K}^{+}\right]_{\mathrm{o}}$ and 
$\left[\mathrm{Na}^{+}\right]_{\mathrm{i}}$ increases the pump rate and enhances the hyperpolarizing pump current. Hence, to determine the intrinsic mechanism that modulates excitability, we first investigated the behavior of the model in response to variations in extracellular potassium and intracellular sodium concentrations.

\section{The effects of $\left[\mathrm{K}^{+}\right]_{\mathrm{o}}$ and $[\mathrm{Na}]_{i}$ on the network model}

172 Activity-dependent changes in ion concentrations are slow compared to neuronal dynamics,

173 which are relatively fast. To analyze such a system, with slow and fast timescales, it is possible 174 to decouple the fast variables (e.g., membrane potential) from the slow variables (e.g., ionic 175 concentrations). Accordingly, to analyze the role of $\left[\mathrm{K}^{+}\right]_{\mathrm{o}}$ and $\left[\mathrm{Na}^{+}\right]_{\mathrm{i}}$ in shaping single-cell and 176 network dynamics, we disabled all mechanisms controlling ionic concentrations and analyzed 177 the behavior of the model for different values of $\left[\mathrm{K}^{+}\right]_{\mathrm{o}}$ and $\left[\mathrm{Na}^{+}\right]_{\mathrm{i}}$. The values of these variables 178 were modified externally and treated as control parameters. In the single cell analysis, all 179 synaptic connections were removed. In the network analysis, all synaptic connections were intact 180 except afferent excitatory input, which was removed from PY cells to eliminate the stochastic 181 component from the analysis; depolarizing current injection was removed from the interneuron.

182 The behavior of a single PY cell was analyzed for different values of extracellular potassium in 183 the dendritic $\left(\left[\mathrm{K}^{+}\right]_{\mathrm{o}, \text { dend }}\right)$ and somatic compartments $\left(\left[\mathrm{K}^{+}\right]_{\mathrm{o} \text {,soma }}\right)$. During the analysis, for each

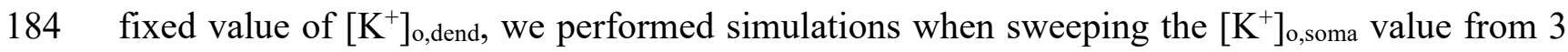
$\mathrm{mM}$ to $14 \mathrm{mM}$ (in steps of $0.25 \mathrm{mM}$ ) in the forward and backward direction. The initial conditions for each $\left[\mathrm{K}^{+}\right]_{\text {o,soma }}$ corresponded to the final states in the previous step. For each

$187\left[\mathrm{~K}^{+}\right]_{\mathrm{o}, \text { soma }}$ step, we simulated 5 seconds of activity. After a full sweep with all $\left[\mathrm{K}^{+}\right]_{\mathrm{o}, \text { soma }}$ steps in 188 both directions, the $\left[\mathrm{K}^{+}\right]_{\mathrm{o} \text {,dend }}$ was increased and the analysis was repeated. The analysis was 189 performed for the $\left[\mathrm{K}^{+}\right]_{\mathrm{o} \text {,dend }}$ values in the range of 3-7 mM, in steps of $0.5 \mathrm{mM}$ (or $0.25 \mathrm{mM}$ if a 190 better resolution was required). We found that the behavior of the single cell and network models 191 was the same for increasing and decreasing steps of $\left[\mathrm{K}^{+}\right]_{\mathrm{o} \text {,soma }}$ with small domains of bistability 192 not larger than one step $(0.25 \mathrm{mM})$ between the activity phases. Analysis of the dynamics of a 193 single isolated cell for a reference value of $\left[\mathrm{Na}^{+}\right]_{\mathrm{i}}$ at $10 \mathrm{mM}$ can be found in Supplementary 194 material (Fig. S1). In the network analysis, a full sweep with all $\left[\mathrm{K}^{+}\right]_{\mathrm{o}, \text { soma }}$ and $\left[\mathrm{K}^{+}\right]_{\text {o,dend }}$ steps (as 195 described above) was performed for three different values of $\left[\mathrm{Na}^{+}\right] \mathrm{i}$, namely, $10 \mathrm{mM}, 11 \mathrm{mM}$ 196 and $12 \mathrm{mM}$. We assumed, that $\left[\mathrm{Na}^{+}\right]_{\mathrm{i}}$ in the dendritic and somatic compartments were equal. In 197 the model simulation shown in Fig. $2 \mathrm{E},\left[\mathrm{Na}^{+}\right]_{\mathrm{i}, \mathrm{dend}}$ values were lower than $\left[\mathrm{Na}^{+}\right]_{\mathrm{i} \text {,soma values. }}$ 198 Accordingly, our assumption may have led to an overestimation of $\left[\mathrm{Na}^{+}\right]$i,dend and the dendritic 
$199 \mathrm{Na}^{+} / \mathrm{K}^{+}$-pump current. The analysis results are shown in Fig. 4A, in which the various activity

200 patterns, i.e., rest, tonic firing and bursting are color-coded (shown on the right). A comparison

201 of the network activities for different values of $\left[\mathrm{Na}^{+}\right]_{\mathrm{i}}$ in the three graphs in Fig. 4A demonstrates

202 that the main effect of an increase in $\left[\mathrm{Na}^{+}\right]_{i}$ was a shrinking of the tonic and bursting domains

203 and an expansion of the resting domain due to upregulation of the hyperpolarizing effect of

204 increased $\left[\mathrm{Na}^{+}\right]_{\mathrm{i}}$ on the pump current.

\section{The evolution of the SLE mediated by $\left[\mathrm{K}^{+}\right]_{0}$ and $[\mathrm{Na}]_{\mathrm{i}}$}

206 In the previous section, the influence of $\left[\mathrm{K}^{+}\right]_{\mathrm{o}}$ and $[\mathrm{Na}]_{\mathrm{i}}$ on network behavior was examined

207 without accounting for the time factor. Here, we present a fast-slow system analysis approach

208 that considers the time evolution of ionic concentrations, as shown in Fig. 2. Hence, we assessed

209 the dependence of the evolution of an SLE on externally manipulated changes in $\left[\mathrm{K}^{+}\right]_{\mathrm{o}}$ and $[\mathrm{Na}]_{\mathrm{i}}$

210 with fixed concentrations of all other ions. To obtain improved affinity with the reference

211 simulation (Fig. 2), the chloride concentration in the dendritic compartment of the PY cells was

212 set to $7.5 \mathrm{mM}$, which corresponded to its peak value during the SLE (Fig. 2F). To schematically

213 describe the extracellular potassium time course from preictal to postictal state (as shown in Fig.

214 2D), we identified four distinct stages (as shown in Fig. 4B top panel): I) a sharp increase in

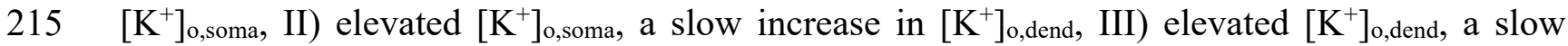

216 decrease in $\left.\left[\mathrm{K}^{+}\right]_{\mathrm{o} \text {,soma, }} \mathrm{IV}\right)$ a decrease in $\left[\mathrm{K}^{+}\right]_{\mathrm{o} \text {,soma }}$ and $\left[\mathrm{K}^{+}\right]_{\mathrm{o} \text {,dend }}$ back to their resting values.

217 Variations in potassium concentrations were accompanied by changes in $\left[\mathrm{Na}^{+}\right]_{i}$ (Fig. 2E). In the

218 preictal period and during the SLE tonic firing phase, $\left[\mathrm{Na}^{+}\right]_{\mathrm{i}}$ in the soma and dendrite was stable,

219 while it increased during the burst firing phase and reached a plateau toward the end of the

220 episode. In the postictal period, $\left[\mathrm{Na}^{+}\right]_{\mathrm{i}}$ in both compartments slowly returned to the initial value.

221 The time course of $\left[\mathrm{Na}^{+}\right]_{\mathrm{i}}$ approximating intracellular somatic sodium evolution is shown in Fig.

222 4B (middle panel). For simplicity, we assumed that these depicted $\left[\mathrm{Na}^{+}\right]$i variations were the

223 same in the dendritic and somatic compartments. The corresponding representative PY cell

224 activity is shown in Fig. 4B (bottom trace). To distinguish different SLE phases, the PY cell

225 activity pattern was marked using a color-code, as in Fig. 4A. As $\left[\mathrm{K}^{+}\right]_{\mathrm{o}}$ and $\left[\mathrm{Na}^{+}\right]_{\mathrm{i}}$ followed their

226 predefined time course, PY cells exhibited transitions from rest to tonic firing, progressed into

227 bursting with a slowing-down pattern and eventually returned to the resting state. In the postictal

228 period (after stage IV), the $\left[\mathrm{Na}^{+}\right]_{\mathrm{i}}$ remained elevated for approximately 40 seconds (Fig. 4B

229 middle panel) giving rise to an enhanced hyperpolarizing $\mathrm{Na}^{+} / \mathrm{K}^{+}$-pump current that reduced the

230 excitability of the network and contributed to postictal depression, as described in the last 
paragraph (Fig. 7). To further observe the time evolution of the SLE in the $\left[\mathrm{K}^{+}\right]_{\mathrm{o}, \text { soma, }}\left[\mathrm{K}^{+}\right]_{\mathrm{o} \text {,dend }}$ parameter space, we superimposed potassium changes on the bifurcation diagrams in Fig. 4A.

233 The distinct stages of the potassium time course are marked by arrows. The crossing of a border

234 by an arrow corresponds to a transition between different firing regimes. The initial increase of 235 somatic $\left[\mathrm{K}^{+}\right]_{\mathrm{o}}$ (stage I) led to a transition from the resting state to tonic firing (Fig. 4A, first 236 panel), while a subsequent increase of dendritic $\left[\mathrm{K}^{+}\right]_{\mathrm{o}}$ (stage II) led to a transition from tonic 237 firing to bursting (Fig. 4A, middle panel). A subsequent decrease in somatic $\left[\mathrm{K}^{+}\right]_{\mathrm{o}}$ (stage III) led 238 to the termination of the SLE, as the cell activity reentered the resting state region (Fig. 4A, last 239 panel). After termination of the SLE, $\left[\mathrm{K}^{+}\right]_{\mathrm{o} \text {,soma }}$ and $\left[\mathrm{K}^{+}\right]_{\mathrm{o} \text {,dend }}$ returned to their resting values 240 (stage IV in Fig. 4A, last panel).

A
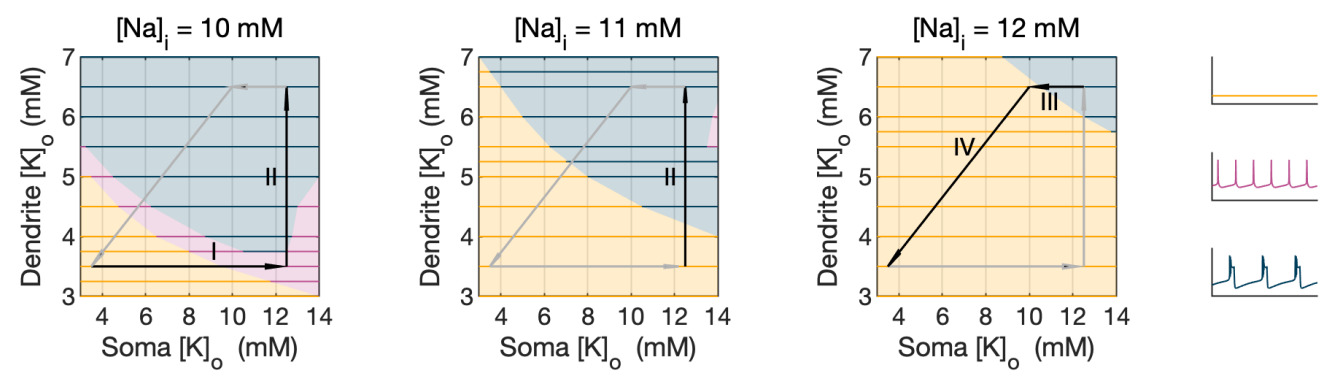

B
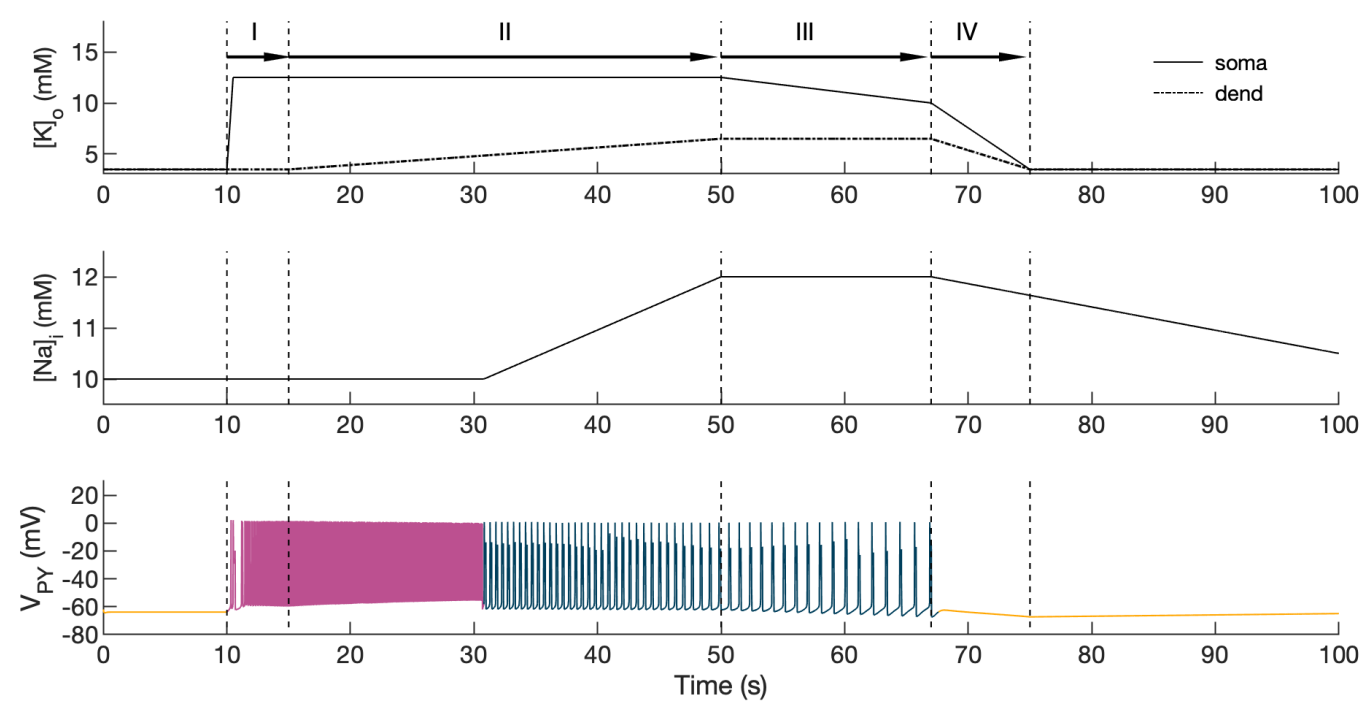

242 Figure 4. A bifurcation diagram of the model. In the bifurcation analysis extracellular

243 potassium and intracellular sodium concentrations in the PY and IN cells were control 244 parameters. Concentrations of all other ions were fixed at their reference values (except chloride: $245\left[\mathrm{Cl}^{-}\right]_{\mathrm{i} \text {,dend }}=7.5 \mathrm{mM}$ ), all ion accumulation mechanisms were blocked and background input was 246 removed. (A) Bifurcation diagrams showing the dependence of the behavior of the model on 
$\left[\mathrm{K}^{+}\right]_{\mathrm{o} \text {,dend }}$ and $\left[\mathrm{K}^{+}\right]_{\mathrm{o} \text {,soma }}$ for varying values of $\left[\mathrm{Na}^{+}\right]_{\mathrm{i}}$. The diagram colors correspond to types of activity shown on the right: rest (yellow), tonic firing (violet) and bursting (dark blue). An increase in $[\mathrm{Na}+]$ I progressively decreased the domains of tonic firing and bursting and increased the resting domain indicating a general decrease in network excitability. The black and gray arrows correspond to the evolution of $\left[\mathrm{K}^{+}\right]_{\mathrm{o}, \text { soma }},\left[\mathrm{K}^{+}\right]_{\mathrm{o} \text {,dend }}$ during different phases of the SLE,

252 shown in part B. (B) A simulation of the model with $\left[\mathrm{K}^{+}\right]_{\mathrm{o}, \text { soma }},\left[\mathrm{K}^{+}\right]_{\mathrm{o} \text {,dend }}$ and $\left[\mathrm{Na}^{+}\right]_{\mathrm{i}}$ as the 253 external control parameters, that illustrated the occurrence of transitions between different types 254 of activity during the SLE. The top two panels show the time course of $\left[\mathrm{K}^{+}\right]_{\mathrm{o}, \text { soma, }}\left[\mathrm{K}^{+}\right]_{\mathrm{o} \text {,dend }}$ and $255\left[\mathrm{Na}^{+}\right]_{i}$ and approximate their evolution during the SLE (Fig. 2). The third panel shows the 256 resulting PY cell behavior. The parameter evolution is divided into four phases indicated by the 257 arrows denoted as I-IV in part $\mathbf{A}$ and $\mathbf{B}$. Phase I corresponds to a sharp increase in $\left[\mathrm{K}^{+}\right]_{\mathrm{o}, \text { soma }}$ 258 which led to a transition from rest to tonic firing (marked as a black arrow ' $I$ ' in the first panel 259 in A). Phase II corresponds to a slow increase in $\left[\mathrm{K}^{+}\right]_{\mathrm{o}, \mathrm{den}}$ which led to a transition from tonic 260 firing to bursting (marked as a black arrow 'II' in the first and second panels in A). Phase III

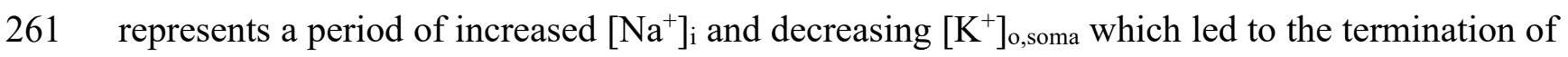
262 the SLE (represented by a black arrow 'III' with its tip in the yellow domain in the third panel 263 in A). Phase IV corresponds to the postictal period with elevated $\left[\mathrm{Na}^{+}\right]_{\mathrm{i}}$ and a return of $\left[\mathrm{K}^{+}\right]_{\mathrm{o}, \text { soma, }}$ $264\left[\mathrm{~K}^{+}\right]_{\mathrm{o}, \mathrm{dend}}$ to their baseline values (marked as a black arrow 'IV' in the third panel in $\mathbf{A}$ ).

\section{The role of $\left[\mathrm{Cl}^{-}\right]_{\mathrm{i}}$}

266 Chloride accumulation depends on $\mathrm{Cl}^{-}$currents, but it is also affected by variations in potassium 267 concentrations mediated via KCC2 cotransport. Hence, chloride and potassium could not be 268 considered as independent control parameters in the fast-slow system analysis approach. 269 Furthermore, visualization of the results with four control parameters $\left(\left[\mathrm{K}^{+}\right]_{\mathrm{o}, \text { soma, }}\left[\mathrm{K}^{+}\right]_{\mathrm{o}, \mathrm{dend}},\left[\mathrm{Na}^{+}\right]_{\mathrm{i}}\right.$ 270 and $\left.\left[\mathrm{Cl}^{-}\right]_{\mathrm{i}}\right)$ is challenging. Therefore, to evaluate the role of chloride accumulation, we compared 271 the reference model with the model in which chloride dynamics was excluded (Fig. 5). In these 272 simulations, afferent excitatory input was removed from the PY cells to eliminate the stochastic 273 component from the analysis. When considering the role of chloride homeostasis mediated via $274 \mathrm{KCC} 2$, the direction of $\mathrm{K}-\mathrm{Cl}$ cotransport depends on the ratio $\left[\mathrm{K}^{+}\right]_{\mathrm{i}}\left[\mathrm{Cl}^{-}\right]_{\mathrm{i}} /\left[\mathrm{K}^{+}\right]_{\mathrm{o}}\left[\mathrm{Cl}^{-}\right]_{\mathrm{o}} .(\mathrm{J}$. A. Payne 275 et al., 2003) If $\left[\mathrm{Cl}^{-}\right]_{\mathrm{i}}$ is greater than $\left[\mathrm{K}^{+}\right]_{\mathrm{o}}$ (disregarding the changes in $\left[\mathrm{K}^{+}\right]_{\mathrm{i}}$ and $\left[\mathrm{Cl}^{-}\right]_{\mathrm{o}}$, which are 276 relatively small), the ratio is greater than 1 and $\mathrm{KCC} 2$ extrudes $\mathrm{Cl}^{-}$and $\mathrm{K}^{+}$. If $\left[\mathrm{K}^{+}\right]_{\mathrm{o}}$ is greater 277 than $\left[\mathrm{Cl}^{-}\right]_{\mathrm{i}}$, the $\mathrm{KCC} 2$ flow is reversed and $\mathrm{Cl}^{-}$and $\mathrm{K}^{+}$ions are transported into the cell. When 278 chloride accumulation was removed (Fig. 5A), the reversal potentials of the $\mathrm{Cl}^{-}$and GABAa 
currents ( $E_{C l}$ and $E_{G A B A a}$ ) were fixed (blue and violet lines in Fig. 5A, second panel). Under such conditions, the firing of the interneuron (Fig. 5A, third panel) exerted a steady inhibitory influence on the PY cells. Additionally, it increased $\left[\mathrm{K}^{+}\right]_{\mathrm{o}}$ above fixed $\left[\mathrm{Cl}^{-}\right]_{\mathrm{i}}$ level (Fig. 5A, fourth panel). As a result, the $\mathrm{KCC} 2$ transported $\mathrm{K}^{+}$and $\mathrm{Cl}^{-}$into the cells (Fig. 5A, bottom panel) and reduced the external $\mathrm{K}^{+}$concentration. All these effects prevented the PY cells from firing and the SLE was not manifested, as seen in the LFP signal which displayed only low amplitude fast activity (Fig. 5A, top panel) mediated by GABAa inhibitory postsynaptic currents (IPSC). Conversely, activation of the IN in the reference model, with chloride accumulation intact, led to a typical SLE (Fig. 5B, top panel). The chloride dynamics increased the excitability in three ways: i) it increased the chloride reversal potential (blue line in Fig. 5B, second panel) toward the PY membrane potential and reduced the hyperpolarizing chloride leak current; ii) it increased

290 the GABAa reversal potential that approached the PY cell membrane potential (violet line in 291 Fig. 5B, second panel), reducing the postsynaptic inhibitory current and iii) it contributed to $292\left[\mathrm{~K}^{+}\right]_{\mathrm{o}}$ accumulation as increased $\left[\mathrm{Cl}^{-}\right]_{\mathrm{i}}$ reduced the inflow of $\mathrm{Cl}^{-}$and $\mathrm{K}^{+}$into the cell via $\mathrm{KCC} 2$ 293 (Fig. 5B, bottom panel).
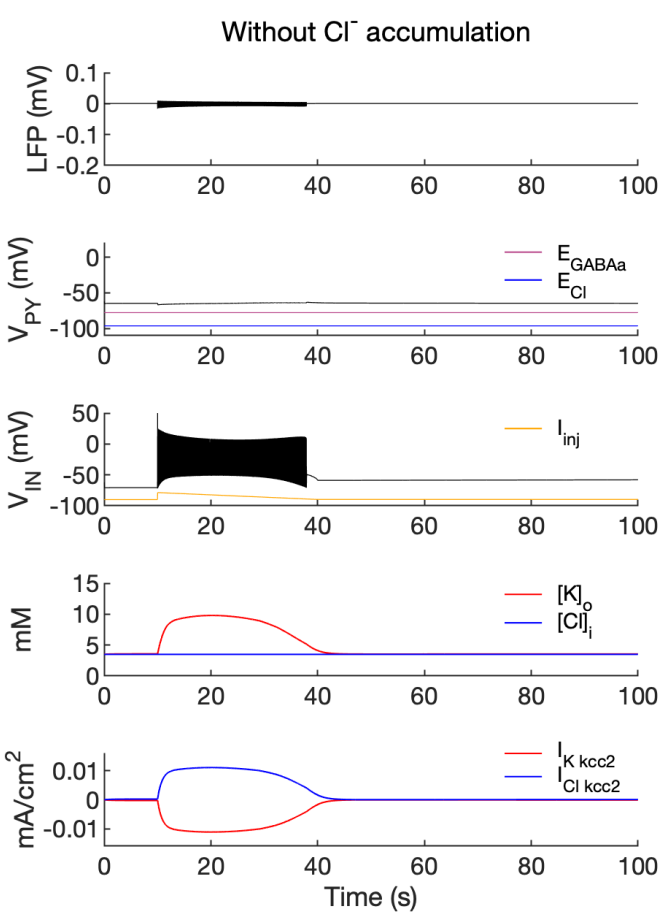

B
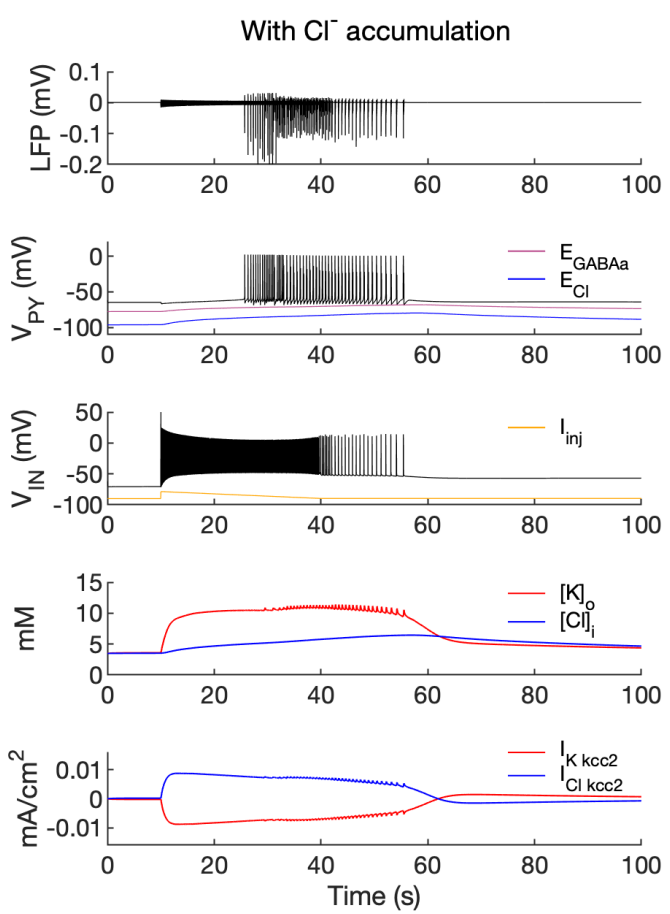

295 Figure 5. A comparison of the model without and with chloride accumulation. The five 296 panels in each column show (from top to bottom): the LFP signal, the PY cell membrane potential, the IN membrane potential, the extracellular potassium concentration and intracellular chloride concentration combined with the chloride and potassium $\mathrm{KCC} 2$ currents in the somatic 
compartments, respectively. Additionally, the equilibrium potential of chloride and GABAa are

300 shown in the second panel from the top. In $\mathbf{A}$ and $\mathbf{B}$, the background input was removed to

301 exclude the stochastic component. (A) When the $\left[\mathrm{Cl}^{-}\right] \mathrm{i}$ accumulation mechanism was blocked,

302 the chloride concentration was fixed at the reference value (fourth panel). Without chloride

303 accumulation, the PY cell remained inhibited (second panel) by the IN discharge triggered by

304 the current injection (yellow, third panel). Additionally, elevated $\left[\mathrm{K}^{+}\right]_{\mathrm{o}}$ and fixed $\left[\mathrm{Cl}^{-}\right]_{\mathrm{i}}$ promoted

$305 \mathrm{~K}^{+}$influx via $\mathrm{KCC} 2$ (bottom panel, red), thus lowering $\left[\mathrm{K}^{+}\right]_{\mathrm{o}}$ and further preventing the

306 generation of the SLE. (B) With chloride accumulation, the IN discharge led to an increase in

$307 E_{C l}$ and $E_{G A B A a}$ (second panel, blue and violet) which reduced the hyperpolarizing $I_{C l, l e a k}$ and

$308 I_{G A B A a}$ currents and enhanced excitability. The increased $\left[\mathrm{Cl}^{-}\right]_{\mathrm{i}}$ reduced $\mathrm{K}^{+}$influx via $\mathrm{KCC} 2$

309 (bottom panel, red) which led to prolonged $\left[\mathrm{K}^{+}\right]_{\mathrm{o}}$ accumulation (fourth panel, red). All three

310 effects contributed to the SLE.

\section{Model predictions}

312 The computer model generated predictions about features that were not explicitly implemented

313 but were consequences of the elementary neurobiological mechanisms used to create the model.

314 These phenomena are described below. The experimental confirmation of features predicted by

315 a model is an essential step in model validation.

The evolution of the inter-burst interval duration

317 It is well known that muscle jerking during the clonic phase of tonic-clonic seizure slows down

318 before ceasing when seizure ends (Bromfield et al., 2006). Frequency slowing has also been

319 observed in video sequences (Kalitzin et al., 2016) and electrographic counterparts of a seizure

320 revealed by either EEG (Franaszczuk et al., 1998; Schiff et al., 2000) or EMG (Conradsen et al.,

321 2013). In the model, a gradual increase in the interval between ictal bursts (IBI) was visible (Fig.

322 2A and $3 \mathrm{~B}$ ). To observe the evolution of the IBI more precisely, the background noise was

323 removed from the simulation and was compensated with a steady depolarizing current of $6 \mathrm{pA}$

324 injected into the somas of all PY cells to preserve the duration of the SLE. A simulated SLE 325 trace and the detected ictal bursts (short bars) are shown in Fig. 6A (top panel). The evolution of

326 the IBI is shown below with either a linear (Fig. 6A, middle panel) or logarithmic (Fig. 6A, 327 bottom panel) y-axis. The IBI on the semi-log graph laid on a straight line suggesting an 328 exponential relationship. The evolution of the IBI during an SLE in a whole-brain in vitro 329 preparation (Fig. 6B) and a human TLE seizure (Fig. 6C) exhibited the same characteristics. An 
A
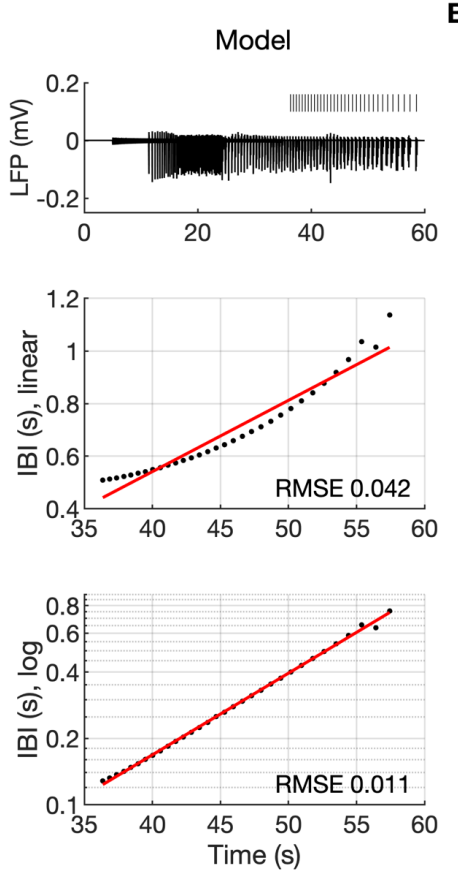

B
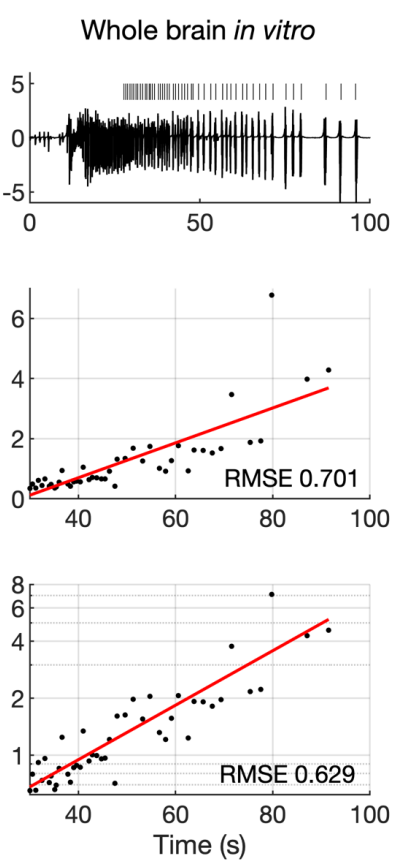
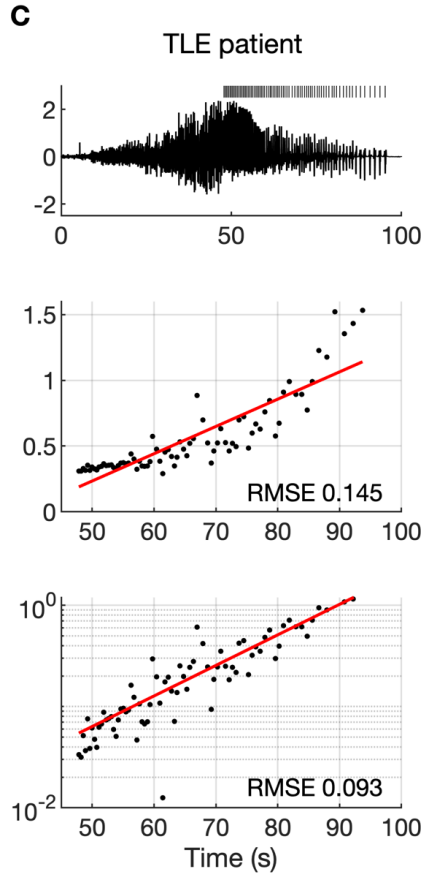

333 Figure 6. The evolution of IBI in the model and experimental data. (A) In the simulation, the background input was removed and compensated with a small depolarizing current injected into the PY cells to preserve the duration of the SLE. A decreasing rate of bursting is visible in the LPF signal and in the detected bursts marked above the trace (top panel). The evolution of the IBI is shown with the $y$-axis on a linear scale (middle panel) and a log scale (bottom). On a linear $y$-axis plot, the data appear curved while on a semi-log plot they lay on a straight line, suggesting exponential scaling of the IBI with time. The red line in each plot represents the best fit for the detected IBI; linear function (middle panel) and exponential function providing a linear relationship on a semi-log plot (bottom panel). The root mean square error (RMSE) between the data points and fitted function is shown in each window. The exponential function fit yielded a smaller RMSE compared to the linear fit, providing quantitative confirmation that at the end of

344 the simulated SLE, the IBI duration increased exponentially, rather than linearly, with time. (B)

345 The evolution of the IBI during the SLE induced by application of bicuculline in the whole-brain 346 in vitro preparation (Boido et al., 2014; Gnatkovsky et al., 2008). (C) IBI evolution during a seizure recorded with intracerebral electrodes positioned in the temporal lobe in a patient submitted to presurgical evaluation (courtesy of Laura Tassi, Epilepsy Surgery Center, Niguarda 
350 and the exponential fit resulted in a smaller RMSE compared to the linear fit, validating the

351 model prediction of an exponential increase in the IBI at the end of a seizure. The linear fit, $I B I(t)$

$352=A+B t$, was obtained using the polyfit procedure, while the exponential function, $I B I(t)=$

$353 A+B \exp (C t)$, was fitted using the fminsearch procedure in Matlab.

\section{The postictal period}

355 An additional model prediction concerned the postictal period which is characterized by reduced 356 excitability and firing. As shown in Fig. 2A-C, after the termination of a seizure there was an 357 approximate 30 - to 50-second period during which firing was either absent or reduced with 358 respect to the interictal period. The exact duration of the postictal period was difficult to assess, 359 as the gap in firing after the SLE was dependent on background fluctuations. To directly 360 investigate the network excitability, we analyzed the responsiveness of the model to external 361 periodic stimulation (see Boido et al. (2014)). The background noise was removed and was 362 compensated with a steady depolarizing current, as in Fig. 6. Stimulation was delivered by 363 activating the excitatory synapses every 5 seconds at each PY soma (arrows in Fig. 7B). The 364 amplitude of the excitatory postsynaptic current (EPSC) was set at just above the threshold for 365 triggering the spike in the interictal period (before the timestamp at 60 seconds). The external 366 stimulation triggered two burst responses after the SLE termination (Fig. 7, vertical broke line) 367 and failed to trigger a suprathreshold response for approximately 40 seconds afterwards. In line 368 with the PY response pattern, no response to the simulated stimulation was observed in the LFP 369 signal during the postictal suppression period (Fig. 7A). The high excitability immediately after 370 termination of the SLE (timestamps between seconds 110 and 120) was correlated with elevated $371\left[\mathrm{~K}^{+}\right]_{\mathrm{o}}$ which was present shortly after the SLE (Fig. 7C). The subsequent postictal reduction of 372 excitability was associated with decay of $\left[\mathrm{K}^{+}\right]_{\mathrm{o}}$ and an increased hyperpolarizing $\mathrm{Na}^{+} / \mathrm{K}^{+}$-pump 373 current that decayed with a slower time constant associated with a gradual clearance of $\left[\mathrm{Na}^{+}\right]_{\mathrm{i}}$ by 374 the pump (Fig. 7D). 


\section{A}

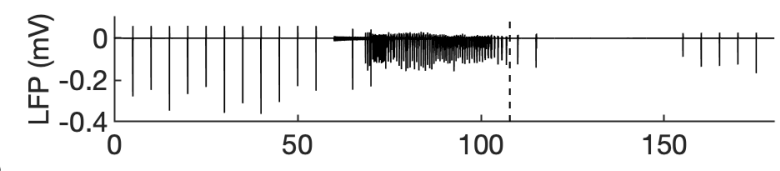

B
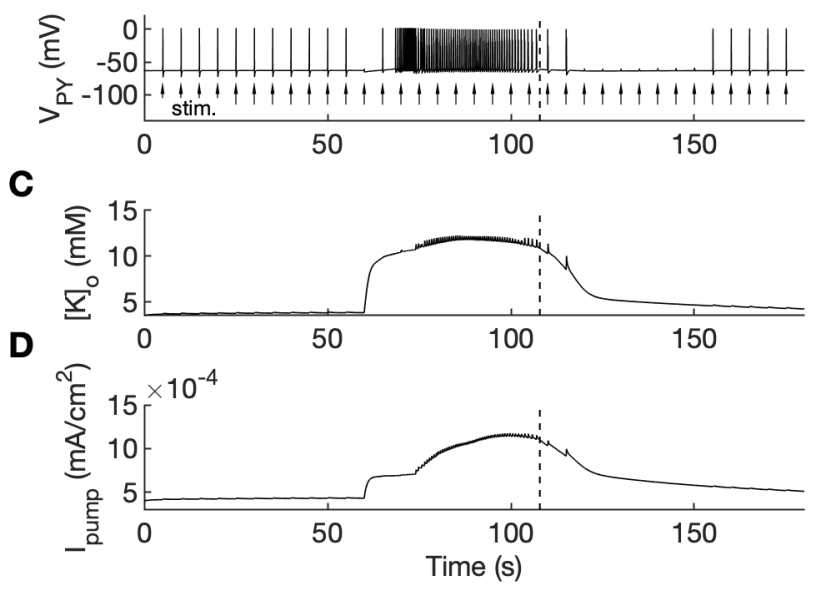

376 Figure 7. An analysis of network excitability in the postictal period. In this figure, the

377 background input was removed from the simulation and compensated with a small depolarizing

378 current injected into the PY cells, as in Fig. 6. (A) The LFP signal. (B) The PY cell membrane

379 potential with external periodic stimulation delivered every 5 seconds, marked by the arrows.

380 The amplitude of the stimulation was set at just above the threshold for triggering a spike in the

381 interictal period. (C) The extracellular potassium in the somatic compartment. (D) The net

$382 \mathrm{Na}^{+} / \mathrm{K}^{+}$-pump current in the somatic compartment. The vertical broken line in all panels marks

383 the SLE offset time without periodic stimulation. Immediately after termination of the SLE, the

384 network was still excitable due to increased $\left[\mathrm{K}^{+}\right]_{\mathrm{o}}$. Shortly afterward, the excitability decreased

385 due to an increased $\mathrm{Na}^{+} / \mathrm{K}^{+}$-pump current that outlasted the increase in $\left[\mathrm{K}^{+}\right]_{\mathrm{o}}$. Increased $I_{\text {pump }}$ and

386 decreased $\left[\mathrm{K}^{+}\right]_{\mathrm{o}}$ which occurred shortly after the termination of the SLE, led to a postictal period

387 during which the network did not respond to external stimulation for approximately 40 seconds.

\section{Discussion}

389 The present study aimed to better define the mechanisms underlying focal seizures. The ictal 390 pattern most frequently observed in human and experimental TLE, i.e., the LVF onset pattern,

391 exhibits a stereotypical sequence of fast activity, irregular spiking and periodic bursting (as 392 shown in Fig. 3A, first panel) (Avoli et al., 2016; de Curtis \& Avoli, 2016; Devinsky et al., 2018; 393 Velascol et al., 2000). We successfully reproduced this pattern in the computer model by 
transiently increasing the firing of the IN. After this trigger, the simulated SLE phases evolved another are mediated by feedback mechanisms between neuronal activities, ion concentration changes and ion homeostasis processes. The distinct mechanisms that shape the activities at various seizure stages are discussed below.

\section{Seizure initiation}

There is increasing evidence showing that seizures with LVF onset are initiated by discharges of fast-spiking GABAergic interneurons (de Curtis \& Avoli, 2016; de Curtis \& Gnatkovsky, 2009; Devinsky et al., 2018). Intracellular chloride accumulation and the elevation of $\left[\mathrm{K}^{+}\right]_{\mathrm{o}}$ due to

403 interneuron activity leads to subsequent depolarization of PY cells and seizure development.

404 Increased interneuron discharges and decreased PY activity around the time of seizure onset were first evidenced in in vitro and in vivo animal models (Gnatkovsky et al., 2008; Grasse et al., 2013; Lévesque et al., 2016; Lopantsev \& Avoli, 1998; Miri et al., 2018; Toyoda et al., 2015; Ziburkus et al., 2006). A similar scenario was observed with single-unit recordings performed during intracerebral presurgical monitoring in neocortical and temporal lobe epilepsy patients

409 (Elahian et al., 2018; Truccolo et al., 2011). The hypothesis that seizure initiation is related to an 410 elevation in $\left[\mathrm{K}^{+}\right]_{\mathrm{o}}$ caused by a strong initial discharge has been tested in computational models 411 with ion concentration changes. In these simulations, seizure-like activity has been induced by 412 DC stimulation of the PY cells alone (Bazhenov et al., 2004; Buchin et al., 2016; Kager et al., 413 2002), by a brief increase in $\left[\mathrm{K}^{+}\right]_{\mathrm{o}}$ (Fröhlich et al., 2006), by stimulation of the IN and PY cells 414 (Ho \& Truccolo, 2016) or by varying the extracellular concentration of $\mathrm{K}^{+}$and $\mathrm{O}_{2}$. (Wei et al., 415 2014) The initial in silico tests on seizure initiation by selective involvement of fast-spiking 416 interneurons were conducted earlier by us (Gentiletti et al., 2017) and others (González et al., 417 2018). We demonstrated that an increase in interneuron firing triggered a transition to a self418 sustained SLE. González et al. (2018) showed that interneuron stimulation by current pulses led 419 to the development of an SLE via a gradual increase in $\left[\mathrm{K}^{+}\right]_{\mathrm{o}}$ mediated by $\mathrm{Cl}^{-}$-dependent 420 activation of the KCC2 cotransporter. In our present model, the IN was activated by a 421 depolarizing, decreasing current ramp of 30 seconds. Initially, the IN discharge led to the 422 silencing of the PY cells, which was correlated with low amplitude fast activity in the LFP signal. 423 The sustained interneuron activity caused a gradual increase in $\left[\mathrm{Cl}^{-}\right]_{\mathrm{i}}$ and $\left[\mathrm{K}^{+}\right]_{\mathrm{o}}$ in the PY cells. 424 The increase in $\left[\mathrm{K}^{+}\right]_{\mathrm{o}}$ produced a positive shift in the $\mathrm{K}^{+}$reversal potential which led to a 425 reduction in the $\mathrm{K}^{+}$leak current and membrane depolarization. The accumulation of $\left[\mathrm{Cl}^{-}\right]_{\mathrm{i}}$ 
increased the $\mathrm{Cl}^{-}$reversal potential and decreased the driving force of the $\mathrm{Cl}^{-}$ions, which led to a reduction in GABAa IPSC and the $\mathrm{Cl}^{-}$leak current. A depolarization in the $E_{K}, E_{C l}$ and $E_{G A B A a}$, and a weakening of the associated hyperpolarizing currents resulted in a gradual depolarization of the PY cells and sustained firing, which was correlated with the tonic SLE phase.

To address the role of potassium and chloride accumulation in seizure initiation, we considered the elevation of $\left[\mathrm{K}^{+}\right]_{\mathrm{o}}$ and $\left[\mathrm{Cl}^{-}\right]_{\mathrm{i}}$ separately. As shown in Fig. 5, a selective increase in $\left[\mathrm{K}^{+}\right]_{\mathrm{o}}$ with a fixed concentration of $\mathrm{Cl}^{-}$did not trigger an SLE. The same result was observed when $\left[\mathrm{Cl}^{-}\right]_{\mathrm{i}}$ was increased and the concentration of $\left[\mathrm{K}^{+}\right]_{\mathrm{o}, \mathrm{i}}$ remained fixed (not shown). This suggests that in our model, a change in the concentrations of either $\left[\mathrm{K}^{+}\right]_{\mathrm{o}}$ or $\left[\mathrm{Cl}^{-}\right]_{\mathrm{i}}$ was not sufficient to initiate an SLE and that an increase in both is necessary. These findings corroborate

436 the results of a study by Alfonsa et al. (2015) which demonstrated that optogenetic chloride 437 loading of PY cells did not trigger ictal events, while the addition of a subictal dose of 4aminopyridine (4-AP) led to full ictal activity.

The observation that the development of seizures may be related to an increase in $\left[\mathrm{K}^{+}\right]_{\mathrm{o}}$

440 beyond the physiological values suggests that the modulation of $\left[\mathrm{K}^{+}\right]_{\mathrm{o}}$ by the use of $\mathrm{K}^{+}$chelators

441 is a potential strategy for the control of seizures. Moreover, in our previous work, we

442 demonstrated that an artificial potassium buffer, which mimicked the function of astrocytes by 443 balancing neuronal $\mathrm{K}^{+}$release, could reduce neuronal excitability and prevent an SLE 444 (Suffczynski et al., 2017).

\section{The mechanisms of $\left[\mathrm{K}^{+}\right]_{\mathrm{o}}$ accumulation}

446 A question arises: what causes $\left[\mathrm{K}^{+}\right]_{\mathrm{o}}$ accumulation? The buildup of $\mathrm{Cl}^{-}$inside the PY neurons 447 during interneuron-induced GABA release results in the activation of the KCC2 cotransporter, 448 which extrudes $\mathrm{Cl}^{-}$and $\mathrm{K}^{+}$into the extracellular space. This hypothesis is supported by in vitro 449 experiments which showed that activation of GABAa receptors led to an increase in $\left[\mathrm{K}^{+}\right]_{\mathrm{o}}$ and 450 cell depolarization, which were eliminated by the KCC2 inhibitor, furosemide (Viitanen et al., 451 2010). The above-mentioned hypothesis is also consistent with the findings that the application 452 of the KCC2 blockers VU0240551 and bumetanide prevented SLEs during 4-AP application in 453 rat brain slices (Hamidi \& Avoli, 2015). However, it is not clear whether the ictal activity is 454 consistently based on $\mathrm{K}^{+}$efflux through $\mathrm{KCC} 2$. In the pilocarpine model, the enhancement of $455 \mathrm{KCC} 2$ in principal cortical neurons is associated with a reduction in seizure duration (Magloire 456 et al., 2019). Based on these results, the authors suggested that KCC2 activity does not affect 
seizure initiation, but influences seizure maintenance during a prolonged period of $\mathrm{Cl}^{-}$ accumulation. The antiepileptic role of enhanced KCC2 activity has also been suggested by Moore et al. (2018), who showed that KCC2 potentiation delayed the onset of an SLE after 4-

460 AP application in vitro and reduced the severity of kainate-induced seizures in vivo. When 461 considering the role of $\mathrm{KCC} 2$ in $\left[\mathrm{K}^{+}\right]_{\mathrm{o}}$ accumulation, it is necessary to note that the direction and 462 magnitude of $\mathrm{KCC} 2$ transport depend on the concentration gradients of $\mathrm{Cl}^{-}$and $\mathrm{K}^{+}$(Kaila et al., 463 2014). Under normal conditions, when $\left[\mathrm{K}^{+}\right]_{\mathrm{o}}$ is sufficiently controlled by homeostatic 464 mechanisms, GABAergic activity leads to the extrusion of $\mathrm{Cl}^{-}$and $\mathrm{K}^{+}$. However, an increase in $465\left[\mathrm{~K}^{+}\right]_{\mathrm{o}}$ may reverse the $\mathrm{K}^{+}-\mathrm{Cl}^{-}$cotransport, thus contributing to $\left[\mathrm{K}^{+}\right]_{\mathrm{o}}$ buffering rather than 466 accumulation (Payne, 1997; Thompson \& Gahwiler, 1989) The activation of IN in our model 467 led to a rapid increase in $\mathrm{K}^{+}$in the narrow extracellular interstitial compartments, while 468 intracellular $\mathrm{Cl}^{-}$accumulation was more gradual (Fig. 2). This generated an influx of $\mathrm{K}^{+}$and $\mathrm{Cl}^{-}$ 469 via $\mathrm{KCC} 2$ (Fig. 5B), which led to $\left[\mathrm{K}^{+}\right]_{\mathrm{o}}$ buffering and $\left[\mathrm{Cl}^{-}\right]_{\mathrm{i}}$ accumulation. The exclusion of $470 \mathrm{KCC} 2$ involvement in the increase in $\left[\mathrm{K}^{+}\right]_{\mathrm{o}}$ suggests that the primary mechanism of $\left[\mathrm{K}^{+}\right]_{\mathrm{o}}$ 471 accumulation in our model was due to other processes, such as the outward $\mathrm{K}^{+}$current that repolarizes action potentials in activated IN and PY cells. This observation is consistent with in vivo experimental evidence that showed a significant local $\left[\mathrm{K}^{+}\right]_{\mathrm{o}}$ rise due to increased spiking activity following electrical stimulation of the cat cerebral cortex (Heinemann \& Lux, 1975).

\section{The tonic-to-bursting transition}

Potassium ions released by interneuron discharges initially diffused to the somatic extracellular compartments of the PY cells and contributed to PY soma depolarization and tonic firing, as described above. Subsequently, $\mathrm{K}^{+}$diffusion from the somatic to dendritic compartments promoted regenerative dendritic spikes in PY cells (Fig. 2D). High $\left[\mathrm{K}^{+}\right]_{\mathrm{o}}$ in the soma and

480 dendrites favored burst firing (Supplementary Fig. S1) through the reduction of repolarizing $\mathrm{K}^{+}$ currents, the activation of a $\mathrm{Na}^{+}$persistent current, and a shift from spike after-hyperpolarization toward depolarizing after-potentials. Prolonged depolarization led to the activation of slow Mtype $\mathrm{K}^{+}$conductance (Supplementary Fig. S2), which hyperpolarized the PY cells after a series of fast spikes. The bursting mechanism in our model originated from currents used in the original entorhinal cortex cells model (Fransen et al., 2002) and was similar to the mechanism in CA1 neurons (Golomb et al., 2006). 


\section{Seizure termination}

489 Various mechanisms underlying seizure termination have been suggested (Lado \& Moshé, 2008;

490 Zubler et al., 2014), however, researchers have not yet reached a consensus regarding which one

491 plays a dominant role. In our model, the SLE terminated spontaneously. Following the fast-slow

492 analysis approach (Fröhlich et al., 2006) we created a simplified model in which $\left[\mathrm{K}^{+}\right]_{\mathrm{o}, \text { soma, }}$

$493\left[\mathrm{~K}^{+}\right]_{\mathrm{o}, \text { dend }}$ and $\left[\mathrm{Na}^{+}\right]_{\mathrm{i}}$ were treated as control parameters. Hence, the influence of neuronal activity

494 on ionic variations was removed and the dependence of network activity on $\mathrm{K}^{+}$and $\mathrm{Na}^{+}$

495 concentrations was analyzed (Fig. 4A). When the time course of the concentration changes of

496 these two ions were tuned to reproduce the decrease in $\left[\mathrm{K}^{+}\right]_{\mathrm{o}}$ and increased level of $\left[\mathrm{Na}^{+}\right]_{\mathrm{i}}$

497 observed in the late SLE phase, the ictal activity spontaneously terminated (Fig. 4B). This

498 indicates that SLE cessation in the model can be explained by two coincident factors, namely

499 the decrease in $\left[\mathrm{K}^{+}\right]_{\mathrm{o}}$ during stable levels of increased $\left[\mathrm{Na}^{+}\right]_{\mathrm{i}}$. An increase in $\left[\mathrm{Na}^{+}\right]_{\mathrm{i}}$ led to an

500 increased hyperpolarizing $\mathrm{Na}^{+} / \mathrm{K}^{+}$-pump current, which increased the firing threshold in the

501 neurons. The increased pump activity also contributed to a progressive decrease in $\left[\mathrm{K}^{+}\right]_{\mathrm{o}}$.

502 Potassium repolarization currents increased after each burst and eventually prevented the

503 initiation of a new cycle of the oscillation. The idea that negative feedback between $\left[\mathrm{Na}^{+}\right]_{\mathrm{i}}$

504 accumulation and neuronal firing is responsible for seizure termination was first formulated by

505 Jensen \& Yaari (1997). Even though it has not been tested experimentally, this hypothesis is

506 consistent with the observation that the inhibition of $\mathrm{Na}^{+} / \mathrm{K}^{+}$-pump activity occurring during

507 hypoxia prolongs SLE discharges in hippocampal slices with blocked synaptic transmission

508 (Haas \& Jefferys, 1984). It was also observed that a decrease in $\mathrm{Na}^{+}$channel conductance via the

509 antiepileptic drug phenytoin, increased the seizure threshold but prolonged the afterdischarges

510 and seizure durations in the rat kindling model of epilepsy (Ebert et al., 1997). In the

511 computational model developed by the Bazhenov team (Krishnan et al., 2015; Krishnan \&

512 Bazhenov, 2011) and Chizhov et al. (2018), a progressive increase in $\left[\mathrm{Na}^{+}\right]_{\mathrm{i}}$ and activation of the

513 electrogenic $\mathrm{Na}^{+} / \mathrm{K}^{+}$-pump were identified as the primary factor of SLE termination. The seizure

514 termination mechanism in the above-mentioned studies is similar to the mechanism observed in

515 the present study, even though different specifications of neuronal mechanisms, network

516 characteristics and seizure morphologies were used.

517 It should be also noted that activation of the $\mathrm{Na}^{+} / \mathrm{K}^{+}$-pump by $\left[\mathrm{Na}^{+}\right]_{\mathrm{i}}$ is not the only 518 proposed mechanism of seizure termination. An alternative mechanism, also linked to an 519 increase in $\left[\mathrm{Na}^{+}\right]$, is dependent on the $\mathrm{Na}^{+}$-activated $\mathrm{K}^{+}$channels (Igelström, 2013). Moreover, 
many other mechanisms such as acidosis (Ziemann et al., 2008), the upregulation of inhibitory neurons (Wen et al., 2015), glutamate depletion (Lado \& Moshé, 2008), the depolarization block of neurons mediated by $\mathrm{K}^{+}$release from astrocytes (Bragin et al., 1997), after-hyperpolarization due to $\mathrm{K}^{+}$channels (Timofeev \& Steriade, 2004), postburst depression (Boido et al., 2014),

524 increased synchrony (Schindler et al., 2007) and the release of adenosine (During \& Spencer, 525 1992; Uva \& de Curtis, 2020) have been suggested to play a role in seizure termination. The 526 abrupt termination of a seizure across the entire brain requires long-range communication which may involve thalamocortical interactions (Aracri et al., 2018; Evangelista et al., 2015), travelling waves (Martinet et al., 2017; Proix et al., 2018) and ephaptic interactions (Jefferys, 1995;

529 Shivacharan et al., 2019). Multiple neuromodulatory, ionic, synaptic and neuronal components

530 likely cooperate to terminate a seizure. Further insight into these mechanisms may be obtained 531 by their selective blockage (Uva \& de Curtis, 2020), the tracking of EEG signal changes as 532 seizure offset approaches (Boido et al., 2014; Saggio et al., 2020) and from analysis of the 533 duration of postictal suppression (Payne et al., 2018).

\section{Frequency Slowing}

535 The approach of seizure termination is often (but not always) accompanied by an increase in the 536 intervals between successive bursts that form the late seizure phase. Saggio et al. (2020) analyzed 537 frequency slowing in human focal onset seizures and estimated that approximately $40 \%$ 538 exhibited unequivocal discharge slowing down toward the end. Burst frequency slowing was confirmed in a study on the entorhinal cortex of the isolated brain preparation during bicucullineand 4AP-induced SLE (Boido et al., 2014). Our model prediction of the exponential increase in the IBI toward the SLE offset (Fig. 6A) was confirmed with experimental data (Fig. 6BC). These

542 findings are also consistent with those of Bauer et al. (2017), which demonstrated that inter-burst

543 intervals in focal epilepsy patients were predominantly described by the exponential scaling law.

544 Conversely, it has been suggested that depending on the bifurcation which leads to seizure termination, the burst oscillation frequency can be constant or decrease according to the

546 logarithmic or square root relationship (Jirsa et al., 2014). The IBI scaling law depends on the 547 slow process leading to seizure termination. In our model, termination of the seizure was related 548 to the slow evolution of ion concentrations which led to a progressive decrease in excitability, 549 primarily via an increased $\mathrm{Na}^{+} / \mathrm{K}^{+}$-pump rate. The lower the excitability, the more time it took 550 for the burst firing threshold to be reached. Hence, bursts frequency slowing in the model was 551 causally related to variations in ion concentrations. If the time course of the ionic concentrations 
were different, the evolution of the IBI would also shift. Several alternative explanations for the increasing inter-burst intervals have been proposed. Bauer et al. (2017) included a plasticity parameter that progressively decoupled spatially distributed neural mass units based on the synchrony level. This mechanism accounted for seizure termination, exponential IBI increase and the presence of a transient postictal state. In the model of Liou et al. (2020) the IBI was constant during seizure expansion and only when the spatial propagation of ictal discharge ceased, the seizure entered the pre-termination stage with a slowing-down trend. An increase in the IBI in this phase was related to the recovery of inhibition and restoration of the $\mathrm{Cl}^{-}$ concentration gradient. These studies indicate that spatial properties related to seizure propagation and synchrony are other factors that may affect the evolution of the IBI.

\section{The postictal period}

563 Seizures are followed by the suppression of physiological rhythms known as postictal EEG 564 suppression (PES) that lasts for seconds or minutes (Pottkämper et al., 2020). Using the stimulation protocol, we investigated the duration of PES in the model. Our results showed that shortly after termination of the SLE, burst responses were still triggered, however, after few seconds, the excitability decreased and remained reduced for approximately 40 seconds (Fig. 7B). This postictal reduction in excitability was associated with subsequent decay of $\left[\mathrm{K}^{+}\right]_{\mathrm{o}}$ and an increased hyperpolarizing $\mathrm{Na}^{+} / \mathrm{K}^{+}$-pump current, which decreased gradually due to slow clearance of $\left[\mathrm{Na}^{+}\right]_{i}$ by the pump (Fig. 7D). The PES duration in our model is consistent with single-unit recordings in epileptic patients that are suppressed for 5 to 30 seconds after seizure

572 termination (Truccolo et al., 2011). Our in silico-derived prediction that postictal 'silence' 573 depends on the hyperpolarizing $\mathrm{Na}^{+} / \mathrm{K}^{+}$-pump has been previously suggested (Fisher \& 574 Schachter, 2000) and simulated (Krishnan et al., 2015; Krishnan \& Bazhenov, 2011). However,

575 in these models, an increased $\mathrm{Na}^{+} / \mathrm{K}^{+}$-pump rate due to elevated $\left[\mathrm{Na}^{+}\right]_{\text {i }}$ terminated the SLE and 576 reduced $\left[\mathrm{K}^{+}\right]_{\mathrm{o}}$ to below baseline level, resulting in a postictal state via a negative shift in $E_{K}$ and 577 membrane hyperpolarization. A below-reference value of $\left[\mathrm{K}^{+}\right]_{\mathrm{o}}$ was observed after seizure 578 termination (Heinemann et al., 1977) and may lead to decreased excitability. In our model, the 579 postictal state was not associated with $\left[\mathrm{K}^{+}\right]_{\mathrm{o}}$ undershoot, as it decayed to baseline level within a 580 few seconds after the SLE offset (Fig. 7C). This was also observed in several previous studies 581 (Fisher et al., 1976; Futamachi et al., 1974). The findings generated by our computational model 582 suggest that the mechanisms of seizure termination and PES involve ion homeostatic processes 
activated and sustained by the excessive seizure discharges, eventually leading to the cessation

584 of the seizure and restoration of the normal state.

\section{Methods}

\section{Geometry}

587 The cell morphology was based on entorhinal cortex PY cells and an interneuron model (Fransen 588 et al., 2002), further reduced to equivalent cylinder models. The PY consisted of two 589 compartments: a soma with a length of $20 \mu \mathrm{m}$ and a diameter of $15 \mu \mathrm{m}$, and a dendrite with a 590 length of $450 \mu \mathrm{m}$ and a diameter of $6.88 \mu \mathrm{m}$. The interneuron only had a somatic compartment 591 with a length of $20 \mu \mathrm{m}$ and a diameter of $15 \mu \mathrm{m}$. Each compartment was surrounded by its own 592 extracellular space (ECS). The extracellular compartments were embedded in a common bathing 593 medium which represented the surrounding neural tissue and vasculature. The size of the ECS 594 was estimated by the extracellular volume fraction, $\alpha$ defined as the ratio volume of extracellular 595 space/volume of tissue. We used $\alpha=0.131$ which corresponded to the CA1 st. pyramidale and $596 \mathrm{a} \mathrm{K}^{+}$concentration of $3.5 \mathrm{mM}$ (McBain et al., 1990).

\section{Biophysics}

598 The active membrane currents in the PY were the fast $\mathrm{Na}^{+}$and $\mathrm{K}^{+}$currents $\left(I_{N a}\right.$ and $I_{K d r}$, 599 respectively) in both compartments and were responsible for action potential generation; a 600 persistent $\mathrm{Na}^{+}$current, $I_{\mathrm{NaP}}$ in the soma; a high-threshold $\mathrm{Ca}^{2+}$ current, $I_{C a L}$ in both compartments; 601 a calcium-dependent after-hyperpolarization $\mathrm{K}^{+}$current, $I_{K A H P}$ in both compartments; a fast 602 calcium- and voltage-dependent $\mathrm{K}^{+}$current, $I_{K C}$ in both compartments; and a noninactivating 603 muscarinic $\mathrm{K}^{+}$current, $I_{K M}$ in the soma. The IN included only the $I_{N a}$ and $I_{K d r}$ currents responsible 604 for spike generation. All the equations for the active currents were initially based on those 605 described by Fransen et al. (2002), however, an additional modification of the parameters 606 described below was required to account for ionic regulation mechanisms. Simulations were 607 performed using the NEURON simulator with a fixed integration step of $0.05 \mathrm{~ms}$.

609 Passive properties

610 The reversal potentials were obtained via the Nernst equation: 


$$
E_{X}=2.3 \frac{R T}{z F} \log \left(\frac{[X]_{o}}{[X]_{i}}\right)
$$

612 where $[X]_{i}$ and $[X]_{o}$ are intra- and extracellular concentrations, respectively, of the ions. $X=$

$613\left\{\mathrm{Na}^{+}, \mathrm{K}^{+}, \mathrm{Ca}^{2+}, \mathrm{Cl}^{-}\right\}, F$ is the Faraday constant, $R$ is the gas constant, $z$ is the valence of the ions

614 and $T=273,16+32$ is the absolute temperature (Gnatkovsky et al., 2008). A leak current, $I_{l e a k}$,

615 was present in all compartments of both cells and was a sum of the leak currents of $\mathrm{Na}^{+}, \mathrm{K}^{+}$and

$616 \mathrm{Cl}^{-}$, modelled as:

$$
I_{i, l e a k}=g_{i, l e a k}\left(V-E_{i}\right)
$$

618 where $g_{i, l e a k}$ is the leak current conductance of the ion of interest $i=\left\{\mathrm{Na}^{+}, \mathrm{K}^{+}, \mathrm{Cl}^{-}\right\}$. The resting

619 membrane potential was $-62 \mathrm{mV}$ in the pyramidal cell and $-70 \mathrm{mV}$ in the interneuron. The

620 specific axial resistance in both cells was set to $R_{a}=100 \mathrm{Ohm} * \mathrm{~cm}$ and the specific membrane

621 capacitance was set to $C_{m}=1 \mu \mathrm{F} / \mathrm{cm}^{2}$, as in Fransen et al. (2002). Based on the $R_{a}$ and PY cell

622 geometry, the somato-dendritic coupling conductance, $g_{c}$, was calculated as $1.5 \mathrm{mS}$.

\section{Active currents}

625 The original equations used time constant units in seconds (s) and voltage units in volts (V), with

$6260 \mathrm{~V}$ corresponding to the resting membrane potential. All equations were modified to account

627 for the millivolt $(\mathrm{mV})$ and millisecond $(\mathrm{ms})$ units used in our model and the voltage was shifted

628 by $-60 \mathrm{mV}$ to correspond to the membrane potential relative to the extracellular space, which

629 was assumed to be $0 \mathrm{mV}$. Additional modifications of the parameters were required to account

630 for the ionic regulation mechanisms that were not present in the original model. $I_{N a P}$ : the

631 activation gate exponent was 2 and the inactivation gate time constant, $\tau_{h}$, was estimated by

632 fitting the activation function form described by Fransen et al. (2002) to the experimental data

633 (Magistretti \& Alonso, 1999). $I_{K d r}$ : the steady-state activation function, $n_{i n f}$, and the activation

634 gate time constant, $\tau_{n}$, were estimated by empirical fit to the experimental data (Sah et al., 1988).

635 To increase the firing threshold, the activation curve was shifted toward positive potentials by

$63616 \mathrm{mV}$ in the soma and $7 \mathrm{mV}$ in the dendrites. The model generated spontaneous fast spiking

637 otherwise. $I_{K A H P}, I_{K C}$ : these $\mathrm{Ca}^{2+}$-dependent currents were modelled according to the model

638 described by Traub et al. (2003) and were implemented in ModelDB

639 (https://senselab.med.yale.edu/ModelDB/), accession number 20756. Due to the arbitrary units

640 for $\mathrm{Ca}^{2+}$ concentration in Traub's model, we modified the current formula to correspond to $\mathrm{mM}$

641 units and resting level of $\left[\mathrm{Ca}^{2+}\right]_{\mathrm{i}}$ used in our model. In pyramidal cells, the soma and dendrite 

equations:

$$
\begin{gathered}
C \frac{d V_{s}}{d t}=-I_{N a, \text { soma }}-I_{N a P}-I_{K d r, \text { soma }}-I_{C a L}-I_{K A H P}-I_{K C}-I_{K M} \\
-I_{\text {leak }}-I_{N a K p u m p}-I_{\text {Capump }}-g_{c}\left(V_{s}-V_{d}\right)-I_{\text {syn }} \\
C \frac{d V_{d}}{d t}=-I_{N a, \text { dend }}-I_{K d r, \text { dend }}-I_{C a L}-I_{K A H P}-I_{K C}-I_{N a K p u m p}-I_{\text {CaPump }}-g_{c}\left(V_{d}-V_{s}\right) \\
-I_{\text {syn }}
\end{gathered}
$$

Transient sodium current

$$
\begin{aligned}
& I_{N a, \text { soma }}=g_{N a, P Y s o m a} m^{3} h\left(V-E_{N a}\right) \\
& I_{N a, \text { dend }}=g_{N a, P Y d e n d} m^{2} h\left(V-E_{N a}\right)
\end{aligned}
$$

Persistent sodium current:

$$
I_{N a P}=g_{N a P} m^{2} h\left(V-E_{N a}\right)
$$

Delayed rectifier:

$$
\begin{aligned}
& I_{K d r, \text { soma }}=g_{K d r, P Y \text { soma }} n^{4}\left(V-E_{K}\right) \\
& I_{K d r, \text { dend }}=g_{K d r, P Y d e n d} n^{2}\left(V-E_{K}\right)
\end{aligned}
$$

656 High-threshold $\mathrm{Ca}^{2+}$ current:

$$
I_{C a L}=g_{C a L} m^{2}\left(V-E_{C a}\right)
$$

$\mathrm{Ca}^{2+}$-dependent $\mathrm{K}^{+}$(afterhyperpolarization) current:

$$
I_{K A H P}=g_{K A H P} m\left(V-E_{K}\right)
$$

660 Fast $\mathrm{Ca}^{2+}$ - and voltage-dependent $\mathrm{K}^{+}$current

$$
I_{K C}=g_{K C} \min \left(\left[\mathrm{Ca}^{2+}\right]_{i} / 250,1\right) m\left(V-E_{K}\right)
$$

662 Muscarinic current:

$$
I_{K M}=g_{K M} m\left(V-E_{K}\right)
$$

664 Equations of gating variables are given in Table 1. Conductance values are given in Table 2.

666 Table 1. Gating variables of the ionic currents in pyramidal cell model

\begin{tabular}{|c|c|c|}
\hline Current & \multicolumn{2}{|c|}{ Kinetics/time constant (ms) } \\
\hline$I_{\text {Na,soma }}$ & $\alpha_{m}=\frac{0.8(-V-40.8)}{\exp \left(\frac{-V-40.8}{4}\right)-1}$ & $\beta_{m}=\frac{0.7(V-15.8)}{\exp \left(\frac{V-15.8}{5}\right)-1}$ \\
\cline { 2 - 3 } & $\alpha_{h}=0.32 \exp \left(\frac{-V-18}{18}\right)$ & $\beta_{h}=\frac{10}{\exp \left(\frac{-V-18}{5}\right)+1}$ \\
\hline$I_{\text {Na,dendrite }}$ & $\alpha_{m}=\frac{0.32(-V-50.9)}{\exp \left(\frac{-V-50.9}{4}\right)-1}$ & $\beta_{m}=\frac{0.28(V-15.9)}{\exp \left(\frac{V-15.9}{5}\right)-1}$ \\
& &
\end{tabular}




\begin{tabular}{|c|c|c|}
\hline & $\alpha_{h}=0.128 \exp \left(\frac{-V-45}{18}\right)$ & $\beta_{h}=\frac{10}{\exp \left(\frac{-V-22}{5}\right)+1}$ \\
\hline \multirow[t]{2}{*}{$I_{\mathrm{NaP}}$} & $m_{\infty}=\frac{1}{1+\exp \left(\frac{-48.7-V}{4.4}\right)}$ & $\begin{array}{l}\tau_{m} \\
=\frac{1}{\frac{0.091(V+38)}{1-\exp \left(\frac{-V-38}{5}\right)}-\frac{0.062(V+38)}{1-\exp \left(\frac{V+38}{5}\right)}}\end{array}$ \\
\hline & $h_{\infty}=\frac{1}{1+\exp \left(\frac{48.8+V}{9.98}\right)}$ & 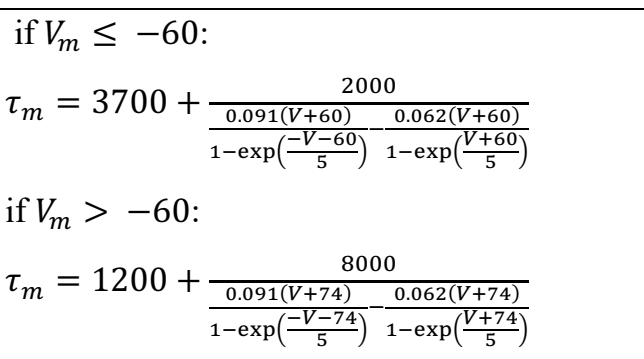 \\
\hline$I_{K d r, s o m a}$ & $n_{\infty}=\frac{1}{1+\exp \left(\frac{-20.8-V}{13.6}\right)}$ & $\begin{array}{l}\tau_{m}=\frac{1.6\left(C+\exp \left(\frac{V}{5}\right)\right)}{D \exp \left(-\frac{V}{40}\right)\left(C+\exp \left(\frac{V}{5}\right)\right)+0.016 \exp \left(\frac{V}{5}\right)(64.9+V)} \\
C=-0.00000230599 ; D=0.0338338\end{array}$ \\
\hline$I_{K d r, \text { dend }}$ & $n_{\infty}=\frac{1}{1+\exp \left(\frac{-11.8-V}{13.6}\right)}$ & $\begin{aligned} \tau_{m} & =\frac{1.6\left(C+\exp \left(\frac{V}{5}\right)\right)}{\operatorname{Dexp}\left(-\frac{V}{40}\right)\left(C+\exp \left(\frac{V}{5}\right)\right)+0.016 \exp \left(\frac{V}{5}\right)(64.9+V)} \\
C & =-0.00000230599 ; D=0.0338338\end{aligned}$ \\
\hline$I_{C a L}$ & $\alpha_{m}=\frac{1.6}{1+\exp (-0.072(V-5))}$ & $\beta_{m}=\frac{0.02(V+8.9)}{\exp \left(\frac{V+8.9}{5}\right)-1}$ \\
\hline$I_{K A H P}$ & $\alpha_{m}=2000\left([\mathrm{Ca}]_{i}-[\mathrm{Ca}]_{i, r e s t}\right)$ & $\beta_{m}=0.01$ \\
\hline$I_{K C}$, if $V_{m} \leq-10$ & $\alpha_{m}=\frac{\exp \left(\frac{V+50}{11}-\frac{V+53.5}{27}\right)}{18.975}$ & $\beta_{m}=2 \exp \left(-\frac{V+53.5}{27}\right)-\alpha_{m}$ \\
\hline$I_{K C}$, if $V_{m}>-10$ & $\alpha_{m}=2 \exp \left(-\frac{V+53.5}{27}\right)$ & $\beta_{m}=0$ \\
\hline$I_{K M}$ & $m_{\infty}=\frac{1}{1+\exp \left(-\frac{V+35}{5}\right)}$ & $\tau_{m}=\frac{1000}{3.3\left[\exp \left(\frac{V+35}{40}\right)\right]+\left[\exp \left(-\frac{V+35}{20}\right)\right]}$ \\
\hline
\end{tabular}

668 Membrane potential of the interneuron was governed by the following Hodgkin-Huxley 669 equations:

$$
C \frac{d V}{d t}=-I_{N a}-I_{K d r}-I_{l e a k}-I_{N a K p u m p}-I_{\text {syn }}-I_{\text {stim }}
$$

671 Current equations, kinetics and time constants of these currents were the same as in pyramidal

672 cell soma. Due to lower resting membrane potential in the interneuron as compared to pyramidal 673 cell, activation curve of $I_{N a}$ was shifted $2 \mathrm{mV}$ towards more negative potential values, while 674 activation curve of $I_{K d r}$ was shifted $14 \mathrm{mV}$ towards more negative potential values. 
Table2. Conductances used in the model

\begin{tabular}{|c|c|c|}
\hline Current conductance & Description & Values $\left(\mathrm{mS} / \mathrm{cm}^{2}\right)$ \\
\hline$g_{N a, l e a k, \mathrm{PY}}$ & $I_{\text {Na,leak }}$ conductance in PY soma and dendrite & $0.9^{*} 10^{-5}$ \\
\hline$g_{K, l e a k, \mathrm{PY}}$ & $I_{K, \text { leak }}$ conductance in PY soma and dendrite & $2.2 * 10^{-5}$ \\
\hline$g_{C l, l e a k, \mathrm{PY}}$ & $I_{C l, \text { leak }}$ conductance in PY soma and dendrite & $1 * 10^{-6}$ \\
\hline$g_{\mathrm{Na}, P Y_{\text {soma }}}$ & $I_{N a}$ conductance in PY soma & 0.02 \\
\hline$g_{N a, P Y d e n d}$ & $I_{N a}$ conductance in PY dendrite & 0.002 \\
\hline$g_{\text {Kdr,PYsoma }}$ & $I_{K d r}$ conductance in PY soma & 0.03 \\
\hline$g_{K d r, P Y d e n d}$ & $I_{K d r}$ conductance in PY dendrite & 0.0035 \\
\hline$g_{\mathrm{NaP}}$ & $I_{N a P}$ conductance in PY soma & $60 * 10^{-5}$ \\
\hline$g_{C a L}$ & $I_{C a L}$ conductance in PY soma and dendrite & $15 * 10^{-5}$ \\
\hline$g_{K A H P}$ & $I_{K A H P}$ conductance in PY soma and dendrite & $5 * 10^{-5}$ \\
\hline$g_{K C}$ & $I_{K C}$ conductance in PY soma and dendrite & $0.196 * 1 \mathrm{e} 3$ \\
\hline$g_{K M}$ & $I_{K M}$ conductance in PY soma & 0.007 \\
\hline$g_{N a, l e a k, I N}$ & $I_{N a, \text { leak }}$ conductance in IN & $0.8 * 10^{-5}$ \\
\hline$g_{K, l e a k, I N}$ & $I_{K, \text { leak }}$ conductance in IN & $2.2 * 10^{-5}$ \\
\hline$g_{C l, l e a k, I N}$ & $I_{C l, \text { leak }}$ conductance in IN & $5 * 10^{-6}$ \\
\hline$g_{N a, I N}$ & $I_{N a}$ conductance in IN & 0.025 \\
\hline$g_{K d r, I N}$ & $I_{K d r}$ conductance in IN & 0.055 \\
\hline
\end{tabular}

\section{Ionic dynamics}

679 The model included six types of ions $\left(\mathrm{K}^{+}, \mathrm{Na}^{+}, \mathrm{Cl}^{-}, \mathrm{Ca}^{2+}, \mathrm{A}^{-}\right.$and $\left.\mathrm{HCO}_{3}^{-}\right)$with variable intra- and

680 extracellular concentrations (except for $\mathrm{HCO}_{3}^{-}$). The evolution of the ion concentrations was based on the following equations:

$$
\frac{d\left[K^{+}\right]_{i}}{d t}=J_{K}^{i}+J_{K, \text { longitudinal }}^{i}+J_{K, K C C 2}^{i}+J_{K, \text { Pump }}^{i}+J_{K, \text { vol }}^{i}
$$

$$
\frac{d\left[K^{+}\right]_{o}}{d t}=J_{K}^{o}+J_{K, \text { radial }}+J_{K, \text { longitudinal }}^{o}+J_{K, \text { bath }}+J_{K, K C C 2}^{o}+J_{K, \text { Pump }}^{o}+J_{g l i a}+J_{K, \text { vol }}^{o}
$$




$$
\frac{d\left[N a^{+}\right]_{i}}{d t}=J_{N a}^{i}+J_{N a, l o n g i t u d i n a l}^{i}+J_{N a, P u m p}^{i}+J_{N a, v o l}^{i}
$$

$$
\frac{d\left[N a^{+}\right]_{o}}{d t}=J_{N a}^{o}+J_{N a, \text { radial }}+J_{N a, \text { longitudinal }}^{o}+J_{N a, b a t h}+J_{N a, P u m p}^{o}+J_{N a, v o l}^{o}
$$

$$
\frac{d\left[C l^{-}\right]_{i}}{d t}=J_{C l}^{i}+J_{C l, G A B A a}^{i}+J_{C l, l o n g i t u d i n a l}^{i}+J_{C l, K C C 2}^{i}+J_{C l, v o l}^{i}
$$

$$
\frac{d\left[C l^{-}\right]_{o}}{d t}=J_{C l}^{o}+J_{C l, G A B A a}^{o}+J_{C l, \text { longitudinal }}^{o}+J_{C l, b a t h}+J_{C l, K C C 2}^{o}+J_{C l, v o l}^{o}
$$

$$
\frac{d\left[\mathrm{Ca}^{2+}\right]_{i, \text { tot }}}{d t}=J_{\text {Ca }}^{i}+J_{\text {Ca,longitudinal }}^{i}+J_{\text {CaPump }}^{i}+J_{\text {Ca,vol }}^{i}
$$

$$
\frac{d\left[\mathrm{Ca}^{+}\right]_{o}}{d t}=J_{C a}^{o}+J_{\text {Ca,longitudinal }}^{o}+J_{\text {CaPump }}^{o}+J_{C a, v o l}^{o}
$$

$$
\frac{d\left[A^{-}\right]_{i}}{d t}=J_{A, v o l}^{i}
$$

691 where $\left[\mathrm{Ca}^{2+}\right]_{\mathrm{i}, \text { tot }}$ is the total intracellular calcium concentration (see calcium buffer below). All

692 fluxes $(\mathrm{mM} / \mathrm{ms})$ are specified below.

\section{Membrane currents}

695 The contribution of transmembrane currents to variations in intra- and extracellular ion concentrations was obtained via the following equations:

$$
\begin{gathered}
J_{X}^{i}=-\frac{\sum I_{X} S}{z F V_{i}} \\
J_{X}^{o}=\frac{\sum I_{X} S}{z F V_{o}}
\end{gathered}
$$

699 where the sum of $I_{X}$ is a net membrane current carrying ion $X, S$ is the surface area of the 700 compartment, $z$ is the valence of the ions, $F$ is the Faraday constant and $V_{i}$ and $V_{o}$ are the volumes 701 of the intra- and extracellular compartments.

Longitudinal diffusion.

704 Longitudinal diffusion of $\mathrm{K}^{+}, \mathrm{Na}^{+}, \mathrm{Ca}^{2+}$ and $\mathrm{Cl}^{-}$was implemented between the somatic and

705 dendritic compartments in the intracellular and extracellular space of the same cell. It was 706 described by Fick's first law:

$$
J_{X, \text { longitudinal }}^{i o}=D_{x} \frac{\left([X]_{i o, a}-[X]_{i o}\right) S}{L V_{i o}}
$$

where $D_{x}$ is the diffusion coefficient for the ion $X,[X]_{i o}$ is the ion concentration in a given intra-

709 or extracellular compartment, $[X]_{o i \text {, a }}$ is the ion concentration in the adjacent compartment, $S$ is 
710 the cross-sectional area between the compartments, $V_{i o}$ is the compartment volume, $L$ is the

711 distance between the centers of the compartments. The diffusion coefficients were (in $\left.\mathrm{um}^{2} / \mathrm{ms}\right)$ :

$712 D_{N a}=1.33, D_{K}=1.96, D_{C a}=0.6, D_{C l}=2.03$ (as in Somjen et al., 2008).

714 Radial diffusion.

$715 \mathrm{Na}^{+}$and $\mathrm{K}^{+}$ions diffused radially between adjacent extracellular compartments modeled as 716 concentric shells around the neurons. The radial exchange of ions between adjacent shells was 717 described by Fick's first law:

$$
J_{X, \text { radial }}=D_{x} \frac{\sum\left([X]_{o, a}-[X]_{o}\right) S}{d r V}
$$

719 where $[X]_{o}$ is the ion concentration in a given shell and the sum goes over all adjacent shells 720 having concentrations $[\mathrm{X}]_{\mathrm{o}}, \mathrm{a}, V$ is a given shell volume, $d r$ is the distance between the centers of 721 the shells and $S$ is the surface contact area between the shells calculated at $16 \%$ of the total outer 722 shell surface. The electrostatic drift of ions was neglected as the ion movement due to the 723 electrical potential gradient in the extracellular space was small compared to the diffusion.

\section{Diffusion to/from the bath}

726 Radial diffusion of $\mathrm{K}^{+}, \mathrm{Na}^{+}$and $\mathrm{Cl}^{-}$between the ECS and the bath was described by Fick's first 727 law:

$$
J_{X, \text { bath }}=\frac{1}{S} D_{x} \frac{\left([X]_{\text {bath }}-[X]_{o}\right) S}{d r V}
$$

729 where $D_{x}$ is the diffusion coefficient for the ion $X, s$ is the scaling constant, $S$ is the outer surface 730 of the shell, $[X]_{\text {bath }}$ is the bath concentration of the ion $X,[X]_{o}$ is the ion concentration in a given

731 shell, $V$ is the shell volume, $d r$ is the distance between the extracellular space and the bath 732 (assumed to be half of the shell thickness). Flux $J_{\text {bath }}$ represents various processes such as 733 diffusion to more distant areas of the brain and cerebrospinal fluid, active transport of potassium 734 into capillaries and potassium spatial buffering by astrocytes. The effective time constant of these 735 joint processes is likely to be much slower than that of radial and longitudinal diffusion and is 736 described by the scaling constant $s=4 * 10^{4}$.

The $\mathrm{Na}^{+} / \mathrm{K}^{+}$pump

739 The $\mathrm{Na}^{+} / \mathrm{K}^{+}$pump was modelled as the sodium and potassium transmembrane currents (Kager 740 et al., 2000):

$$
I_{N a, \text { Pump }}=3 I_{\text {max }} \text { flux }\left(\left[\mathrm{Na}^{+}\right]_{i},\left[\mathrm{~K}^{+}\right]_{o}\right)
$$




$$
I_{K, \text { Pump }}=-2 I_{\max } \operatorname{flux}\left(\left[\mathrm{Na}^{+}\right]_{i},\left[\mathrm{~K}^{+}\right]_{o}\right)
$$

$$
f \operatorname{lux}\left(\left[\mathrm{Na}^{+}\right]_{i},\left[K^{+}\right]_{o}\right)=\left(1+\frac{K m_{K}}{\left[K^{+}\right]_{o}}\right)^{-2}\left(1+\frac{K m_{N a}}{\left[N a^{+}\right]_{o}}\right)^{-3}
$$

with $I_{\max }=0.008 \mathrm{~mA} / \mathrm{cm}^{2}, K m_{K}=2 \mathrm{mM}$ and $K m_{N a}=10 \mathrm{mM}$. As in the previous model, ion concentrations and membrane potentials at rest deviated slightly from the equilibrium conditions, with and without background excitatory synaptic input. This was due to the presence of the $\mathrm{Na}^{+} / \mathrm{K}^{+}$-pump glial buffer and ion diffusion, which cannot be balanced and induce small oscillations around the baseline values.

\section{KCC2 cotransport}

The KCC2 cotransporter currents were modelled according to Wei et al. (2014):

$$
\begin{gathered}
I_{K}=\gamma U_{K C C 2} \log \left(\frac{\left[\mathrm{K}^{+}\right]_{i}\left[C l^{-}\right]_{i}}{\left[\mathrm{~K}^{+}\right]_{o}\left[\mathrm{Cl}^{-}\right]_{o}}\right) \\
I_{C l}=-I_{K}
\end{gathered}
$$

with cotransporter strength, $U_{K C C 2}=0.3 \mathrm{mM} / \mathrm{s}$. Conversion factor $\gamma=(F V) / S$ from $\mathrm{mM} / \mathrm{s}$ units to current density units $\mathrm{mA} / \mathrm{cm}^{2}$ was calculated for soma and dendrites based on the compartment surface area $(S)$, intracellular volume $\left(V_{i}\right)$ and the Faraday constant $(F)$.

\section{Glial uptake}

Potassium uptake by the glia was modelled as a set of differential equations (Kager et al., 2000):

$$
\begin{aligned}
& J_{\text {glia }}=-k_{2}\left[K^{+}\right]_{o}[B]+k_{1}[K B] \\
& \frac{d[B]}{d t}=-k_{2}\left[K^{+}\right]_{o}[B]+k_{1}[K B] \\
& \frac{d[K B]}{d t}=k_{2}\left[K^{+}\right]_{o}[B]-k_{1}[K B]
\end{aligned}
$$

where $[B]$ is the free buffer, $[K B]$ is the bound buffer $\left(=[B]_{\max }-[B]\right), B_{\max }=500 \mathrm{mM} . k_{l}=0.0008$ $\mathrm{ms}^{-1}$ and $k_{2}=\frac{k_{1}}{1+\exp \left(\frac{[K]_{0}-18}{-1.25}\right)}$ are backward and forward rate constants, respectively.

The calcium pump and buffer

767 The calcium pump and buffer which altered the intracellular $\mathrm{Ca}^{2+}$ were modelled according to

768 the model implementation of Somjen et al. (2008) in ModelDB, accession number 113446. The

769 calcium pump which extruded $\mathrm{Ca}^{2+}$ from the cells was modelled as a $\mathrm{Ca}^{2+}$ transmembrane 770 current: 


$$
I_{\text {CaPump }}=\frac{I_{\max }}{1+\frac{K_{\text {pump }}}{\left[\mathrm{Ca}^{2+}\right]_{i}}}
$$

with $I_{\max }=2.55 \mathrm{~mA} / \mathrm{cm}^{2}$ and $K_{\text {pump }}=0.0069 \mathrm{mM}$. Intracellular $\mathrm{Ca}^{2+}$ was buffered by first-order

773 chemical $\mathrm{Ca}^{2+}$ buffer with a total concentration of $[B]_{\mathrm{i}}$ and an equilibrium constant of $K_{d}$.

774 Calcium buffering was fast and under the assumption of equilibrium conditions, the relationship between the total and free intracellular calcium concentrations, $\left[\mathrm{Ca}^{2+}\right]_{\mathrm{i}, \text { tot }}$ and $\left[\mathrm{Ca}^{2+}\right]_{\mathrm{i}}$, was given by (Borgdorff, 2002, pg. 27):

$$
\left[\mathrm{Ca}^{2+}\right]_{i, t o t}=\left[\mathrm{Ca}^{2+}\right]_{i} \frac{[B]_{i}+K_{d}+\left[\mathrm{Ca}^{2+}\right]_{i}}{K_{d}+\left[\mathrm{Ca}^{2+}\right]_{i}}
$$

where $[B]_{\mathrm{i}}=1.562 \mathrm{mM}^{*}\left(V_{i}^{0} / V_{i}\right), V_{i}$ is the intracellular compartment volume, $V_{i}^{0}$ is the intracellular compartment volume at rest and $K_{d}=0.008 \mathrm{mM}$.

\section{Volume changes}

782 Volume changes were modelled according to Somjen et al. (2008). The rates of intra- and extracellular volume changes were proportional to the difference in osmotic pressure between the intra- and extracellular compartments and fulfilled the conservation of total volume.

$$
\frac{d V_{i}}{d t}=\Delta
$$

$$
\frac{d V_{o}}{d t}=-\Delta
$$

787 where

$V_{i}$ and $V_{o}$ are the volumes of the intra- and extracellular compartments and $\tau=250 \mathrm{~ms}$. The constant $\mathrm{c}$ is introduced for unit conversion and is equal to $1 \mathrm{um}^{3} / \mathrm{mM}$, hence units of $\Delta$ are $\mathrm{um}^{3} / \mathrm{ms}$. The extracellular volume was initially $13.1 \%$ of the cellular volume and was allowed to shrink maximally down to $4 \%$. Volume changes affected concentrations but not the total mass of each ion within a compartment. The conservation of mass required additional fluxes: Intracellular

$$
\begin{gathered}
\pi_{i}=\left[\mathrm{Na}^{+}\right]_{i}+\left[\mathrm{K}^{+}\right]_{i}+\left[\mathrm{Cl}^{-}\right]_{i}+\left[\mathrm{Ca}^{2+}\right]_{i}+\left[\mathrm{HCO}_{3}^{-}\right]_{i}+\left[\mathrm{A}^{-}\right]_{i} \\
\pi_{o}=\left[\mathrm{Na}^{+}\right]_{o}+\left[\mathrm{K}^{+}\right]_{o}+\left[\mathrm{Cl}^{-}\right]_{o}+\left[\mathrm{Ca}^{2+}\right]_{o}+\left[\mathrm{HCO}_{3}^{-}\right]_{o}+\left[\mathrm{A}^{-}\right]_{o}
\end{gathered}
$$

$$
J_{X, v o l}^{i}=-\frac{\Delta}{V_{i}}[X]_{i}
$$

Extracellular 


$$
J_{X, v o l}^{o}=\frac{\Delta}{V_{o}}[X]_{o}
$$

\section{Initial ion concentrations}

802 The initial concentrations of $\left[\mathrm{Na}^{+}\right]_{\mathrm{i}},\left[\mathrm{Ca}^{2+}\right]_{\mathrm{i}},\left[\mathrm{Na}^{+}\right]_{\mathrm{o}},\left[\mathrm{K}^{+}\right]_{\mathrm{o}},\left[\mathrm{Ca}^{2+}\right]_{\mathrm{o}}$ and $\left[\mathrm{A}^{+}\right]_{\mathrm{o}}$ were based on

803 Somjen et al. (2008), and the initial concentration of $\left[\mathrm{HCO}_{3}{ }^{-}\right]_{\mathrm{i}}$ was based on Doyon et al. (2011).

804 Chloride concentrations were set to satisfy the thermodynamic equilibrium of $\mathrm{KCC} 2$, i.e., $\left[\mathrm{Cl}^{-}\right]_{\mathrm{o}}$

$805=\left[\mathrm{K}^{+}\right]_{\mathrm{i}}$ and $\left[\mathrm{Cl}^{-}\right]_{\mathrm{i}}=\left[\mathrm{K}^{+}\right]_{\mathrm{o}}$ giving $E_{C l}=E_{K}$. The remaining ions, i.e., $\left[\mathrm{K}^{+}\right]_{\mathrm{i}},\left[\mathrm{A}^{+}\right]_{\mathrm{i}}$ and $\left[\mathrm{HCO}_{3}{ }^{-}\right]_{\mathrm{o}}$

806 were solved to fulfil electroneutrality and osmotic equilibrium conditions. Hence, the initial

807 concentrations were as follows (in $\mathrm{mM}$ ): $\left[\mathrm{Na}^{+}\right]_{\mathrm{i}}=10,\left[\mathrm{Na}^{-}\right]_{\mathrm{o}}=140,\left[\mathrm{~K}^{+}\right]_{\mathrm{o}}=3.5,\left[\mathrm{Ca}^{2+}\right]_{\mathrm{i}}=5 \mathrm{e}-5$,

$808\left[\mathrm{Ca}^{2+}\right]_{\mathrm{o}}=2,\left[\mathrm{~A}^{+}\right]_{\mathrm{o}}=0,\left[\mathrm{HCO}_{3}{ }^{-}\right]_{\mathrm{i}}=15,\left[\mathrm{~K}^{+}\right]_{\mathrm{i}}=136.5,\left[\mathrm{~A}^{+}\right]_{\mathrm{i}}=128,\left[\mathrm{HCO}_{3}{ }^{-}\right]_{\mathrm{o}}=11,\left[\mathrm{Cl}^{-}\right]_{\mathrm{o}}=3.5$ and $809 \quad\left[\mathrm{Cl}^{-}\right]_{\mathrm{i}}=136.5$.

\section{Synaptic connections and model inputs}

812 The pyramidal cells created excitatory AMPA synaptic connections with the interneuron and all

813 other pyramidal cells. The interneuron created an inhibitory GABA $\mathrm{a}_{\mathrm{a}}$ synaptic connection with

814 each pyramidal cell. Excitatory synapses were placed in the middle of the PY dendrite and the

815 middle of the IN soma. Inhibitory synapses were placed in the middle of the PY soma. The time 816 course of synaptic conductance was modelled with a built-in NEURON mechanism Exp2Syn, 817 implementing a dual exponential function:

$$
g=g_{\max }\left[\exp \left(-\frac{t}{\tau_{2}}\right)-\exp \left(-\frac{t}{\tau_{1}}\right)\right]
$$

819 where the rise and decay time constants, $\tau_{1}$ and $\tau_{2}$, were $2 \mathrm{~ms}$ and $6 \mathrm{~ms}$, respectively, for all 820 synapses. $g_{\max }=$ weight*factor, where the factor was defined so that the normalized peak was 1 .

821 The weights for the synapses between the PY and from the PY to the IN were $w_{e e}=0.0006 \mu \mathrm{S}$ 822 and $w_{e i}=0.001 \mu \mathrm{S}$, respectively. The inhibitory synaptic weight, $w_{i e}$, was $0.0003 \mu \mathrm{S}$. All 823 pyramidal cells received background input modelled as a Poisson spike train, which was different 824 in each cell, activated an excitatory synapse at a rate of $5 \mathrm{~Hz}$ and had a synaptic weight $w_{\text {input }}=$ $8250.0005 \mu \mathrm{S}$. To initiate the SLE, a depolarizing ramp current, $I_{i n j}$, was injected into the 826 interneuron, with the initial amplitude of $0.8 \mathrm{nA}$ linearly decreasing toward 0 over 30 seconds.

827 The inhibitory $\mathrm{GABA}_{\mathrm{a}}$ postsynaptic currents were carried by $\mathrm{Cl}^{-}$and $\mathrm{HCO}_{3}{ }^{-}$ions. The receptor 828 pore conducts $\mathrm{Cl}^{-}$and $\mathrm{HCO}_{3}{ }^{-}$at a ratio of 4:1 (Voipio et al., 1991), hence, $E_{G A B A a}$ was calculated 829 as (Doyon et al., 2011): 


$$
E_{G A B A a}=2.3 \frac{R T}{F}\left(\frac{4\left[\mathrm{Cl}^{-}\right]_{i}+\left[\mathrm{HCO}_{3}^{-}\right]_{i}}{4\left[\mathrm{Cl}^{-}\right]_{o}+\left[\mathrm{HCO}_{3}^{-}\right]_{o}}\right)
$$

$831 \mathrm{HCO}_{3}{ }^{-}$concentrations were assumed to be constant and equal to $\left[\mathrm{HCO}_{3}{ }^{-}\right]_{\mathrm{i}}=15 \mathrm{mM}$ and $832\left[\mathrm{HCO}_{3}{ }^{-}\right]_{\mathrm{o}}=11 \mathrm{mM}$.

\section{Calculation of the LFP}

835 The local field potentials were calculated based on all transmembrane currents in all cells using

836 the following equation (Nunez \& Srinivasan, 2006):

$$
\phi(r, t)=\frac{1}{4 \pi \sigma} \sum_{n=1}^{N} \frac{I_{n}(t)}{\left|r-r_{n}\right|}
$$

838 Where $I_{n}$ is a point current source at position $r_{n}$ (taken as the position of a mid-point of a 839 compartment) and $r$ is the position of the electrode. $\sigma=0.3 \mathrm{~S} / \mathrm{m}$ is the extracellular conductivity 840 (Lindén et al., 2014). The electrode was located in the middle of the somatic layer of the PY and

841 IN cells, approximately 16 um from the centers of the somas of two neighbouring PY cells. The 842 currents from the interneuron were taken with a weight of 0.2 to decrease their contribution. 843 Also, the influence of the injected current on the LFP was removed. The amplitude of the 844 simulated LFP signal was an order of magnitude smaller than the experimental data. This was 845 due to current point-source approximation and the small number of cells in the modeled network.

\section{Software Accessibility}

847 If accepted, the model will be publicly available in the ModelDB

848 (https://senselab.med.yale.edu/modeldb/)

\section{Acknowledgements}

850 We are grateful to Laura Uva and Laura Librizzi for helpful discussions throughout the 851 preparation of this work and for providing the SLE data from the in vitro isolated whole guinea 852 pig brain. We thank Laura Tassi from the Claudio Munari Epilepsy Surgery Center of the 853 Niguarda Hospital in Milano, Italy, for providing the intracerebral data on human seizures. The 854 work of MdC and VG was supported by the EPICARE grant of the Associazione Paolo Zorzi 855 for the Neuroscience.

857 The authors report no competing interests. 


\section{References}

859

860

861

862

863

864

865

866

867

868

869

870

871

872

873

874

875

876

877

878

879

880

881

882

883

884

Alfonsa, H., Merricks, E. M., Codadu, N. K., Cunningham, M. O., Deisseroth, K., Racca, C., \& Trevelyan, A. J. (2015). The Contribution of Raised Intraneuronal Chloride to Epileptic Network Activity. Journal of Neuroscience, 35(20), 7715-7726.

https://doi.org/10.1523/JNEUROSCI.4105-14.2015

Aracri, P., de Curtis, M., Forcaia, G., \& Uva, L. (2018). Enhanced thalamo-hippocampal synchronization during focal limbic seizures. Epilepsia, 59(9), 1774-1784. https://doi.org/10.1111/epi.14521

Avoli, M., De Curtis, M., Gnatkovsky, V., Gotman, J., Köhling, R., Lévesque, M., Manseau, F., Shiri, Z., \& Williams, S. (2016). Specific imbalance of excitatory/inhibitory signaling establishes seizure onset pattern in temporal lobe epilepsy. Journal of Neurophysiology, 115(6), 3229-3237. https://doi.org/10.1152/jn.01128.2015

Bauer, P. R., Thijs, R. D., Lamberts, R. J., Velis, D. N., Visser, G. H., Tolner, E. A., Sander, J. W., Lopes da Silva, F. H., \& Kalitzin, S. N. (2017). Dynamics of convulsive seizure termination and postictal generalized EEG suppression. Brain, 140(3), 655-668. https://doi.org/10.1093/brain/aww322

Bazhenov, M., Timofeev, I., Steriade, M., \& Sejnowski, T. J. (2004). Potassium model for slow (2-3 Hz) in vivo neocortical paroxysmal oscillations. Journal of Neurophysiology, 92(2), 1116-1132. https://doi.org/10.1152/jn.00529.2003

Blauwblomme, T., Jiruska, P., \& Huberfeld, G. (2014). Mechanisms of ictogenesis. In International Review of Neurobiology (Vol. 114, pp. 155-185). Academic Press Inc. https://doi.org/10.1016/B978-0-12-418693-4.00007-8

Boido, D., Gnatkovsky, V., Uva, L., Francione, S., \& De Curtis, M. (2014). Simultaneous enhancement of excitation and postburst inhibition at the end of focal seizures. Annals of Neurology, 76(6), 826-836. https://doi.org/10.1002/ana.24193

Borgdorff, J. A. (2002). Calcium dynamics in hippocampal neurones [University of Amsterdam]. https://hdl.handle.net/11245/1.201021 
Bradford, H. F. (1995). Glutamate, GABA and epilepsy. Progress in Neurobiology, 47(6), 477-511. https://doi.org/10.1016/0301-0082(95)00030-5

Bragin, A., Azizyan, A., Almajano, J., \& Engel, J. (2009). The Cause of the Imbalance in the Neuronal Network Leading to Seizure Activity Can Be Predicted by the Electrographic Pattern of the Seizure Onset. Journal of Neuroscience, 29(11), 3660-3671. https://doi.org/10.1523/JNEUROSCI.5309-08.2009

Bragin, Anatol, Penttonen, M., \& Buzsáki, G. (1997). Termination of Epileptic Afterdischarge in the Hippocampus. The Journal of Neuroscience, 17(7), 2567-2579. https://doi.org/10.1523/JNEUROSCI.17-07-02567.1997

Bromfield, E. B., Cavazos, J. E., \& Sirven, J. I. (Eds.). (2006). An Introduction to Epilepsy [Internet]. West Hartford (CT): American Epilepsy Society. https://www.ncbi.nlm.nih.gov/books/NBK2508/

Buchin, A., Chizhov, A., Huberfeld, G., Miles, R., \& Gutkin, B. S. (2016). Reduced efficacy of the KCC2 cotransporter promotes epileptic oscillations in a subiculum network model. Journal of Neuroscience, 36(46), 11619-11633. https://doi.org/10.1523/JNEUROSCI.4228-15.2016

Chizhov, A. V., Zefirov, A. V., Amakhin, D. V., Smirnova, E. Y., \& Zaitsev, A. V. (2018). Minimal model of interictal and ictal discharges "Epileptor-2." PLoS Computational Biology, 14(5), 1-25. https://doi.org/10.1371/journal.pcbi.1006186

Conradsen, I., Moldovan, M., Jennum, P., Wolf, P., Farina, D., \& Beniczky, S. (2013). Dynamics of muscle activation during tonic-clonic seizures. Epilepsy Research, 104(12), 84-93. https://doi.org/10.1016/j.eplepsyres.2012.09.004

de Curtis, M., \& Avoli, M. (2016). GABAergic networks jump-start focal seizures. Epilepsia, 57(5), 679-687. https://doi.org/10.1111/epi.13370

de Curtis, M., \& Gnatkovsky, V. (2009). Reevaluating the mechanisms of focal ictogenesis: The role of low-voltage fast activity. Epilepsia, 50(12), 2514-2525. https://doi.org/10.1111/j.1528-1167.2009.02249.x 
912

913

914

915

916

917

918

919

920

921

922

923

924

925

926

927

928

929

930

931

932

933

934

935

936

937

938

939

de Curtis, M., Librizzi, L., \& Uva, L. (2006). In Vitro Isolated Guinea Pig Brain. In A.

Pitkänen, P. A. Schwartzkroin, \& S. L. Moshé (Eds.), Models of Seizures and Epilepsy (pp. 103-109). Academic Press Inc. https://doi.org/10.1016/B978-012088554-1/50011-6

de Curtis, M., Uva, L., Gnatkovsky, V., \& Librizzi, L. (2018). Potassium dynamics and seizures: Why is potassium ictogenic? Epilepsy Research, 143(April), 50-59. https://doi.org/10.1016/j.eplepsyres.2018.04.005

Derchansky, M., Jahromi, S. S., Mamani, M., Shin, D. S., Sik, A., \& Carlen, P. L. (2008). Transition to seizures in the isolated immature mouse hippocampus: a switch from dominant phasic inhibition to dominant phasic excitation. The Journal of Physiology, 586(2), 477-494. https://doi.org/10.1113/jphysiol.2007.143065

Devinsky, O., Vezzani, A., O’Brien, T. J., Jette, N., Scheffer, I. E., de Curtis, M., \& Perucca, P. (2018). Epilepsy. Nature Reviews Disease Primers, 4(1), 18024. https://doi.org/10.1038/nrdp.2018.24

Doyon, N., Prescott, S. A., Castonguay, A., Godin, A. G., Kröger, H., \& de Koninck, Y. (2011). Efficacy of synaptic inhibition depends on multiple, dynamically interacting mechanisms implicated in chloride homeostasis. PLoS Computational Biology, 7(9). https://doi.org/10.1371/journal.pcbi.1002149

During, M. J., \& Spencer, D. D. (1992). Adenosine: A potential mediator of seizure arrest and postictal refractoriness. Annals of Neurology, 32(5), 618-624. https://doi.org/10.1002/ana.410320504

Ebert, U., Cramer, S., \& Löscher, W. (1997). Phenytoin's effect on the spread of seizure activity in the amygdala kindling model. Naunyn-Schmiedeberg's Archives of Pharmacology, 356(3), 341-347. https://doi.org/10.1007/PL00005060

Elahian, B., Lado, N. E., Mankin, E., Vangala, S., Misra, A., Moxon, K., Fried, I., Sharan, A., Yeasin, M., Staba, R., Bragin, A., Avoli, M., Sperling, M. R., Engel, J., \& Weiss, S. A. (2018). Low-voltage fast seizures in humans begin with increased interneuron firing. Annals of Neurology, 84(4), 588-600. https://doi.org/10.1002/ana.25325

Evangelista, E., Bénar, C., Bonini, F., Carron, R., Colombet, B., Régis, J., \& Bartolomei, F. 
(2015). Does the Thalamo-Cortical Synchrony Play a Role in Seizure Termination? Frontiers in Neurology, 6. https://doi.org/10.3389/fneur.2015.00192

Feng, Z., \& Durand, D. M. (2003). Low-Calcium Epileptiform Activity in the Hippocampus In Vivo. Journal of Neurophysiology, 90(4), 2253-2260. https://doi.org/10.1152/jn.00241.2003

Fisher, R. S., Pedley, T. A., Moody, W. J., \& Prince, D. A. (1976). The Role of Extracellular Potassium in Hippocampal Epilepsy. Archives of Neurology, 33(2), 76-83. https://doi.org/10.1001/archneur.1976.00500020004002

Fisher, Robert S., \& Schachter, S. C. (2000). The Postictal State: A Neglected Entity in the Management of Epilepsy. Epilepsy and Behavior, 1(1), 52-59. https://doi.org/10.1006/ebeh.2000.0023

Franaszczuk, P. J., Bergey, G. K., Durka, P. J., \& Eisenberg, H. M. (1998). Time-frequency analysis using the matching pursuit algorithm applied to seizures originating from the mesial temporal lobe. Electroencephalography and Clinical Neurophysiology, 106(6), 513-521. https://doi.org/10.1016/S0013-4694(98)00024-8

Fransen, E., Alonso, A. A., \& Hasselmo, M. E. (2002). Simulations of the role of the muscarinic-activated calcium-sensitive nonspecific cation current INCM in entorhinal neuronal activity during delayed matching tasks. Journal of Neuroscience, 22(3), 10811097. https://doi.org/10.1523/jneurosci.22-03-01081.2002

Fröhlich, F., Bazhenov, M., Timofeev, I., Steriade, M., \& Sejnowski, T. J. (2006). Slow state transitions of sustained neural oscillations by activity-dependent modulation of intrinsic excitability. Journal of Neuroscience, 26(23), 6153-6162. https://doi.org/10.1523/JNEUROSCI.5509-05.2006

Fujiwara-Tsukamoto, Y., Isomura, Y., Imanishi, M., Fukai, T., \& Takada, M. (2007). Distinct types of ionic modulation of GABA actions in pyramidal cells and interneurons during electrical induction of hippocampal seizure-like network activity. European Journal of Neuroscience, 25(9), 2713-2725. https://doi.org/10.1111/j.1460-9568.2007.05543.x 
969

970

971

972

973

974

975

976

977

978

979

980

981

982

983

984

985

986

987

988

989

990

991

992

993

994

Gentiletti, D., Suffczynski, P., Gnatkovsky, V., \& De Curtis, M. (2017). Changes of Ionic Concentrations during Seizure Transitions-A Modeling Study. International Journal of Neural Systems, 27(4), 1-16. https://doi.org/10.1142/S0129065717500046

Gnatkovsky, V., Librizzi, L., Trombin, F., \& De Curtis, M. (2008). Fast activity at seizure onset is mediated by inhibitory circuits in the entorhinal cortex in vitro. Annals of Neurology, 64(6), 674-686. https://doi.org/10.1002/ana.21519

Golomb, D., Yue, C., \& Yaari, Y. (2006). Contribution of Persistent Na + Current and M-Type $\mathrm{K}+$ Current to Somatic Bursting in CA1 Pyramidal Cells: Combined Experimental and Modeling Study. Journal of Neurophysiology, 96(4), 1912-1926. https://doi.org/10.1152/jn.00205.2006

González, O. C., Shiri, Z., Krishnan, G. P., Myers, T. L., Williams, S., Avoli, M., \& Bazhenov, M. (2018). Role of KCC2-dependent potassium efflux in 4-Aminopyridine-induced Epileptiform synchronization. Neurobiology of Disease, 109(August 2017), 137-147. https://doi.org/10.1016/j.nbd.2017.10.011

Grasse, D. W., Karunakaran, S., \& Moxon, K. A. (2013). Neuronal synchrony and the transition to spontaneous seizures. Experimental Neurology, 248, 72-84. https://doi.org/10.1016/j.expneurol.2013.05.004

Haas, H. L., \& Jefferys, J. G. (1984). Low-calcium field burst discharges of CA1 pyramidal neurones in rat hippocampal slices. The Journal of Physiology, 354(1), 185-201. https://doi.org/10.1113/jphysiol.1984.sp015371

Hamidi, S., \& Avoli, M. (2015). KCC2 function modulates in vitro ictogenesis. Neurobiology of Disease, 79, 51-58. https://doi.org/10.1016/j.nbd.2015.04.006

Heinemann, U., Lux, H. D., \& Gutnick, M. J. (1977). Extracellular free calcium and potassium during paroxysmal activity in the cerebral cortex of the cat. Experimental Brain Research, 27(3-4), 237-243. https://doi.org/10.1007/BF00235500

Heinemann, Uwe, \& Lux, H. D. (1975). Undershoots following stimulus-induced rises of 
extracellular potassium concentration in cerebral cortex of cat. Brain Research, 93(1), 6376. https://doi.org/10.1016/0006-8993(75)90286-3

Ho, Y. E. C., \& Truccolo, W. (2016). Interaction between synaptic inhibition and glialpotassium dynamics leads to diverse seizure transition modes in biophysical models of human focal seizures. Journal of Computational Neuroscience, 41(2), 225-244. https://doi.org/10.1007/s10827-016-0615-7

Igelström, K. M. (2013). Is Slack an Intrinsic Seizure Terminator? The Neuroscientist, 19(3), 248-254. https://doi.org/10.1177/1073858412446311

Jefferys, J. G. (1995). Nonsynaptic modulation of neuronal activity in the brain: electric currents and extracellular ions. Physiological Reviews, 75(4), 689-723. https://doi.org/10.1152/physrev.1995.75.4.689

Jefferys, J. G. R., \& Haas, H. L. (1982). Synchronized bursting of CA1 hippocampal pyramidal cells in the absence of synaptic transmission. Nature, 300(5891), 448-450. https://doi.org/10.1038/300448a0

Jefferys, J., Jiruska, P., de Curtis, M., \& Avoli, M. (2012). Limbic Network Synchronization and Temporal Lobe Epilepsy. In J. Noebels, M. Avoli, M. Rogawski, R. Olsen, \& A. Delgado-Escueta (Eds.), Jasper's Basic Mechanisms of the Epilepsies. Bethesda (MD): National Center for Biotechnology Information (US). http://www.ncbi.nlm.nih.gov/pubmed/22787650

Jensen, M. S., \& Yaari, Y. (1997). Role of intrinsic burst firing, potassium accumulation, and electrical coupling in the elevated potassium model of hippocampal epilepsy. Journal of Neurophysiology, 77(3), 1224-1233. https://doi.org/10.1152/jn.1997.77.3.1224

Jirsa, V. K., Stacey, W. C., Quilichini, P. P., Ivanov, A. I., \& Bernard, C. (2014). On the nature of seizure dynamics. Brain, 137(8), 2210-2230. https://doi.org/10.1093/brain/awu133

Kager, H., Wadman, W. J., \& Somjen, G. G. (2000). Simulated Seizures and Spreading Depression in a Neuron Model Incorporating Interstitial Space and Ion Concentrations. Journal of Neurophysiology, 84(1), 495-512. https://doi.org/10.1152/jn.2000.84.1.495 
Kager, H., Wadman, W. J., \& Somjen, G. G. (2002). Conditions for the triggering of spreading depression studied with computer simulations. Journal of Neurophysiology, 88(5), 27002712. https://doi.org/10.1152/jn.00237.2002

Kaila, K., Price, T. J., Payne, J. A., Puskarjov, M., \& Voipio, J. (2014). Cation-chloride cotransporters in neuronal development, plasticity and disease. Nature Reviews Neuroscience, 15(10), 637-654. https://doi.org/10.1038/nrn3819

Kalitzin, S. N., Bauer, P. R., Lamberts, R. J., Velis, D. N., Thijs, R. D., \& Da Silva, F. H. L. (2016). Automated Video Detection of Epileptic Convulsion Slowing as a Precursor for Post-Seizure Neuronal Collapse. International Journal of Neural Systems, 26(8), 100104. https://doi.org/10.1142/S0129065716500271

Krishnan, G. P., \& Bazhenov, M. (2011). Ionic dynamics mediate spontaneous termination of seizures and postictal depression state. Journal of Neuroscience, 31(24), 8870-8882. https://doi.org/10.1523/JNEUROSCI.6200-10.2011

Krishnan, G. P., Filatov, G., Shilnikov, A., \& Bazhenov, M. (2015). Electrogenic properties of the $\mathrm{Na}+/ \mathrm{K}+$ ATPase control transitions between normal and pathological brain states. Journal of Neurophysiology, 113(9), 3356-3374. https://doi.org/10.1152/jn.00460.2014

Lado, F. A., \& Moshé, S. L. (2008). How do seizures stop? Epilepsia, 49(10), 1651-1664. https://doi.org/10.1111/j.1528-1167.2008.01669.x

Lagarde, S., Buzori, S., Trebuchon, A., Carron, R., Scavarda, D., Milh, M., McGonigal, A., \& Bartolomei, F. (2019). The repertoire of seizure onset patterns in human focal epilepsies: Determinants and prognostic values. Epilepsia, 60(1), 85-95. https://doi.org/10.1111/epi.14604

Lévesque, M., Herrington, R., Hamidi, S., \& Avoli, M. (2016). Interneurons spark seizure-like activity in the entorhinal cortex. Neurobiology of Disease, 87, 91-101. https://doi.org/10.1016/j.nbd.2015.12.011

Lian, J., Bikson, M., Shuai, J., \& Durand, D. M. (2001). Propagation of non-synaptic epileptiform activity across a lesion in rat hippocampal slices. Journal of Physiology, 537(1), 191-199. https://doi.org/10.1111/j.1469-7793.2001.0191k.x 
Lillis, K. P., Kramer, M. A., Mertz, J., Staley, K. J., \& White, J. A. (2012). Pyramidal cells accumulate chloride at seizure onset. Neurobiology of Disease, 47(3), 358-366. https://doi.org/10.1016/j.nbd.2012.05.016

1053

Lindén, H., Hagen, E., Łeski, S., Norheim, E. S., Pettersen, K. H., \& Einevoll, G. T. (2014). LFPy: A tool for biophysical simulation of extracellular potentials generated by detailed model neurons. Frontiers in Neuroinformatics, 7(JAN), 1-15. https://doi.org/10.3389/fninf.2013.00041

Liou, J., Smith, E. H., Bateman, L. M., Bruce, S. L., McKhann, G. M., Goodman, R. R., Emerson, R. G., Schevon, C. A., \& Abbott, L. (2020). A model for focal seizure onset, propagation, evolution, and progression. ELife, 9. https://doi.org/10.7554/eLife.50927

Lopantsev, V., \& Avoli, M. (1998). Participation of GABA(A)-mediated inhibition in ictallike discharges in the rat entorhinal cortex. Journal of Neurophysiology, 79(1), 352-360. https://doi.org/10.1152/jn.1998.79.1.352

Magistretti, J., \& Alonso, A. (1999). Biophysical Properties and Slow Voltage-Dependent Inactivation of a Sustained Sodium Current in Entorhinal Cortex Layer-II Principal Neurons. Journal of General Physiology, 114(4), 491-509. https://doi.org/10.1085/jgp.114.4.491

Magloire, V., Cornford, J., Lieb, A., Kullmann, D. M., \& Pavlov, I. (2019). KCC2 overexpression prevents the paradoxical seizure-promoting action of somatic inhibition. Nature Communications, 10(1), 1-13. https://doi.org/10.1038/s41467-019-08933-4

Martinet, L.-E., Fiddyment, G., Madsen, J. R., Eskandar, E. N., Truccolo, W., Eden, U. T., Cash, S. S., \& Kramer, M. A. (2017). Human seizures couple across spatial scales through travelling wave dynamics. Nature Communications, 8(1), 14896. https://doi.org/10.1038/ncomms14896

McBain, C., Traynelis, S., \& Dingledine, R. (1990). Regional variation of extracellular space in the hippocampus. Science, 249(4969), 674-677. https://doi.org/10.1126/science.2382142

Miri, M. L., Vinck, M., Pant, R., \& Cardin, J. A. (2018). Altered hippocampal interneuron 
activity precedes ictal onset. ELife, 7. https://doi.org/10.7554/eLife.40750

1079

1080

1081

1082

1083

1084

1085

1086

1087

1088

1089

1090

1091

1092

1093

1094

1095

1096

1097

1098

1099

1100

1101

1102

1103

1104

Moore, Y. E., Deeb, T. Z., Chadchankar, H., Brandon, N. J., \& Moss, S. J. (2018). Potentiating KCC2 activity is sufficient to limit the onset and severity of seizures. Proceedings of the National Academy of Sciences of the United States of America, 115(40), 10166-10171. https://doi.org/10.1073/pnas.1810134115

Nunez, P. L., \& Srinivasan, R. (2006). Electric Fields of the Brain. Oxford University Press. https://doi.org/10.1093/acprof:oso/9780195050387.001.0001

Payne, D. E., Karoly, P. J., Freestone, D. R., Boston, R., D’Souza, W., Nurse, E., Kuhlmann, L., Cook, M. J., \& Grayden, D. B. (2018). Postictal suppression and seizure durations: A patient-specific, long-term iEEG analysis. Epilepsia, 59(5), 1027-1036. https://doi.org/10.1111/epi.14065

Payne, J. A. (1997). Functional characterization of the neuronal-specific K-Cl cotransporter: Implications for $[\mathrm{K}+](0)$ regulation. American Journal of Physiology - Cell Physiology, 273(5 42-5). https://doi.org/10.1152/ajpcell.1997.273.5.c1516

Payne, J. A., Rivera, C., Voipio, J., \& Kaila, K. (2003). Cation-chloride co-transporters in neuronal communication, development and trauma. Trends in Neurosciences, 26(4), 199206. https://doi.org/10.1016/S0166-2236(03)00068-7

Perucca, P., Dubeau, F., \& Gotman, J. (2014). Intracranial electroencephalographic seizureonset patterns: effect of underlying pathology. Brain, 137(1), 183-196. https://doi.org/10.1093/brain/awt299

Pottkämper, J. C. M., Hofmeijer, J., van Waarde, J. A., \& van Putten, M. J. A. M. (2020). The postictal state — What do we know? Epilepsia, 61(6), 1045-1061. https://doi.org/10.1111/epi.16519

Proix, T., Jirsa, V. K., Bartolomei, F., Guye, M., \& Truccolo, W. (2018). Predicting the spatiotemporal diversity of seizure propagation and termination in human focal epilepsy. Nature Communications, 9(1), 1088. https://doi.org/10.1038/s41467-018-02973-y

Pumain, R., Menini, C., Heinemann, U., Louvel, J., \& Silva-Barrat, C. (1985). Chemical 

synaptic transmission is not necessary for epileptic seizures to persist in the baboon Papio papio. Experimental Neurology, 89(1), 250-258. https://doi.org/10.1016/00144886(85)90280-8

Raimondo, J. V., Burman, R. J., Katz, A. A., \& Akerman, C. J. (2015). Ion dynamics during seizures. Frontiers in Cellular Neuroscience, 9, 1-14. https://doi.org/10.3389/fncel.2015.00419

Saggio, M. L., Crisp, D., Scott, J. M., Karoly, P., Kuhlmann, L., Nakatani, M., Murai, T., Dümpelmann, M., Schulze-Bonhage, A., Ikeda, A., Cook, M., Gliske, S. V, Lin, J., Bernard, C., Jirsa, V., \& Stacey, W. C. (2020). A taxonomy of seizure dynamotypes. ELife, 9. https://doi.org/10.7554/eLife.55632

Schiff, S. J., Colella, D., Jacyna, G. M., Hughes, E., Creekmore, J. W., Marshall, A., BozekKuzmicki, M., Benke, G., Gaillard, W. D., Conry, J., \& Weinstein, S. R. (2000). Brain chirps: spectrographic signatures of epileptic seizures. Clinical Neurophysiology, 111(6), 953-958. https://doi.org/10.1016/S1388-2457(00)00259-5

Schindler, K., Leung, H., Elger, C. E., \& Lehnertz, K. (2007). Assessing seizure dynamics by analysing the correlation structure of multichannel intracranial EEG. Brain, 130(1), 6577. https://doi.org/10.1093/brain/aw1304

Shivacharan, R. S., Chiang, C.-C., Zhang, M., Gonzalez-Reyes, L. E., \& Durand, D. M. (2019). Self-propagating, non-synaptic epileptiform activity recruits neurons by endogenous electric fields. Experimental Neurology, 317, 119-128. https://doi.org/10.1016/j.expneurol.2019.02.005

Somjen, G. G., Kager, H., \& Wadman, W. J. (2008). Computer simulations of neuron-glia interactions mediated by ion flux. Journal of Computational Neuroscience, 25(2), 349365. https://doi.org/10.1007/s10827-008-0083-9

Spencer, S. S., Guimaraes, P., Katz, A., Kim, J., \& Spencer, D. (1992). Morphological Patterns of Seizures Recorded Intracranially. Epilepsia, 33(3), 537-545. https://doi.org/10.1111/j.1528-1157.1992.tb01706.x 
Potassium and Focal Seizures-Insight from In Silico Study. In P. Érdi, B. Sen https://doi.org/10.1007/978-3-319-49959-8_3

Thompson, S. M., \& Gahwiler, B. H. (1989). Activity-dependent disinhibition. II. Effects of extracellular potassium, furosemide, and membrane potential on ECl- in hippocampal CA3 neurons. Journal of Neurophysiology, 61(3), 512-523. https://doi.org/10.1152/jn.1989.61.3.512

Timofeev, I., \& Steriade, M. (2004). Neocortical seizures: initiation, development and cessation. Neuroscience, 123(2), 299-336.

Toyoda, I., Fujita, S., Thamattoor, A. K., \& Buckmaster, P. S. (2015). Unit activity of https://doi.org/10.1016/j.neuroscience.2003.08.051

Traub, R. D., Buhl, E. H., Gloveli, T., \& Whittington, M. A. (2003). Fast Rhythmic Bursting Can Be Induced in Layer 2/3 Cortical Neurons by Enhancing Persistent $\mathrm{Na}+$ Conductance or by Blocking BK Channels. Journal of Neurophysiology, 89(2), 909-921.

Truccolo, W., Donoghue, J. A., Hochberg, L. R., Eskandar, E. N., Madsen, J. R., Anderson, W. S., Brown, E. N., Halgren, E., \& Cash, S. S. (2011). Single-neuron dynamics in human

1155 Uva, L., Breschi, G. L., Gnatkovsky, V., Taverna, S., \& de Curtis, M. (2015). Synchronous inhibitory potentials precede seizure-like events in acute models of focal limbic seizures.

1159 Uva, L., \& de Curtis, M. (2020). Activity- and pH-dependent adenosine shifts at the end of a Journal of Neuroscience, 35(7), 3048-3055. https://doi.org/10.1523/JNEUROSCI.3692focal seizure in the entorhinal cortex. Epilepsy Research, 165, 106401. https://doi.org/10.1016/j.eplepsyres.2020.106401 
1162

1163

1164

1165

1166

1167

1168

1169

1170

1171

1172

1173

1174

1175

1176

1177

1178

1179

1180

1181

1182

1183

1184

1185

1186

1187

1188

1189

Velascol, A. L., Wilson, C. L., Babb, T. L., \& Engel Jr, J. (2000). Functional and Anatomic Correlates of Two Frequently Observed Temporal Lobe Seizure-Onset Patterns. Neural Plasticity, 7(1-2), 49-63. https://doi.org/10.1155/NP.2000.49

Viitanen, T., Ruusuvuori, E., Kaila, K., \& Voipio, J. (2010). The K+-Cl- cotransporter KCC2 promotes GABAergic excitation in the mature rat hippocampus. Journal of Physiology, 588(9), 1527-1540. https://doi.org/10.1113/jphysiol.2009.181826

Voipio, J., Pasternack, M., Rydqvist, B., \& Kaila, K. (1991). Effect of gamma-aminobutyric acid on intracellular $\mathrm{pH}$ in the crayfish stretch-receptor neurone. The Journal of Experimental Biology, 156, 349-360. http://www.ncbi.nlm.nih.gov/pubmed/1711091

Wei, Y., Ullah, G., \& Schiff, S. J. (2014). Unification of neuronal spikes, seizures, and spreading depression. Journal of Neuroscience, 34(35), 11733-11743. https://doi.org/10.1523/JNEUROSCI.0516-14.2014

Wen, B., Qian, H., Feng, J., Ge, R.-J., Xu, X., Cui, Z.-Q., Zhu, R.-Y., Pan, L.-S., Lin, Z.-P., \& Wang, J.-H. (2015). A Portion of Inhibitory Neurons in Human Temporal Lobe Epilepsy are Functionally Upregulated: An Endogenous Mechanism for Seizure Termination. CNS Neuroscience \& Therapeutics, 21(2), 204-214. https://doi.org/10.1111/cns.12336

Yaari, Y., Konnerth, A., \& Heinemann, U. (1983). Spontaneous epileptiform activity of ca1 hippocampal neurons in low extracellular calcium solutions. Experimental Brain Research, 51(1). https://doi.org/10.1007/BF00236813

Ziburkus, J., Cressman, J. R., Barreto, E., \& Schiff, S. J. (2006). Interneuron and pyramidal cell interplay during in vitro seizure-like events. Journal of Neurophysiology, 95(6), 3948-3954. https://doi.org/10.1152/jn.01378.2005

Ziemann, A. E., Schnizler, M. K., Albert, G. W., Severson, M. A., Howard III, M. A., Welsh, M. J., \& Wemmie, J. A. (2008). Seizure termination by acidosis depends on ASIC1a. Nature Neuroscience, 11(7), 816-822. https://doi.org/10.1038/nn.2132

Zubler, F., Steimer, A., Gast, H., \& Schindler, K. A. (2014). Seizure Termination. In International Review of Neurobiology (pp. 187-207). Academic Press Inc. https://doi.org/10.1016/B978-0-12-418693-4.00008-X 


\section{Supplementary figures}
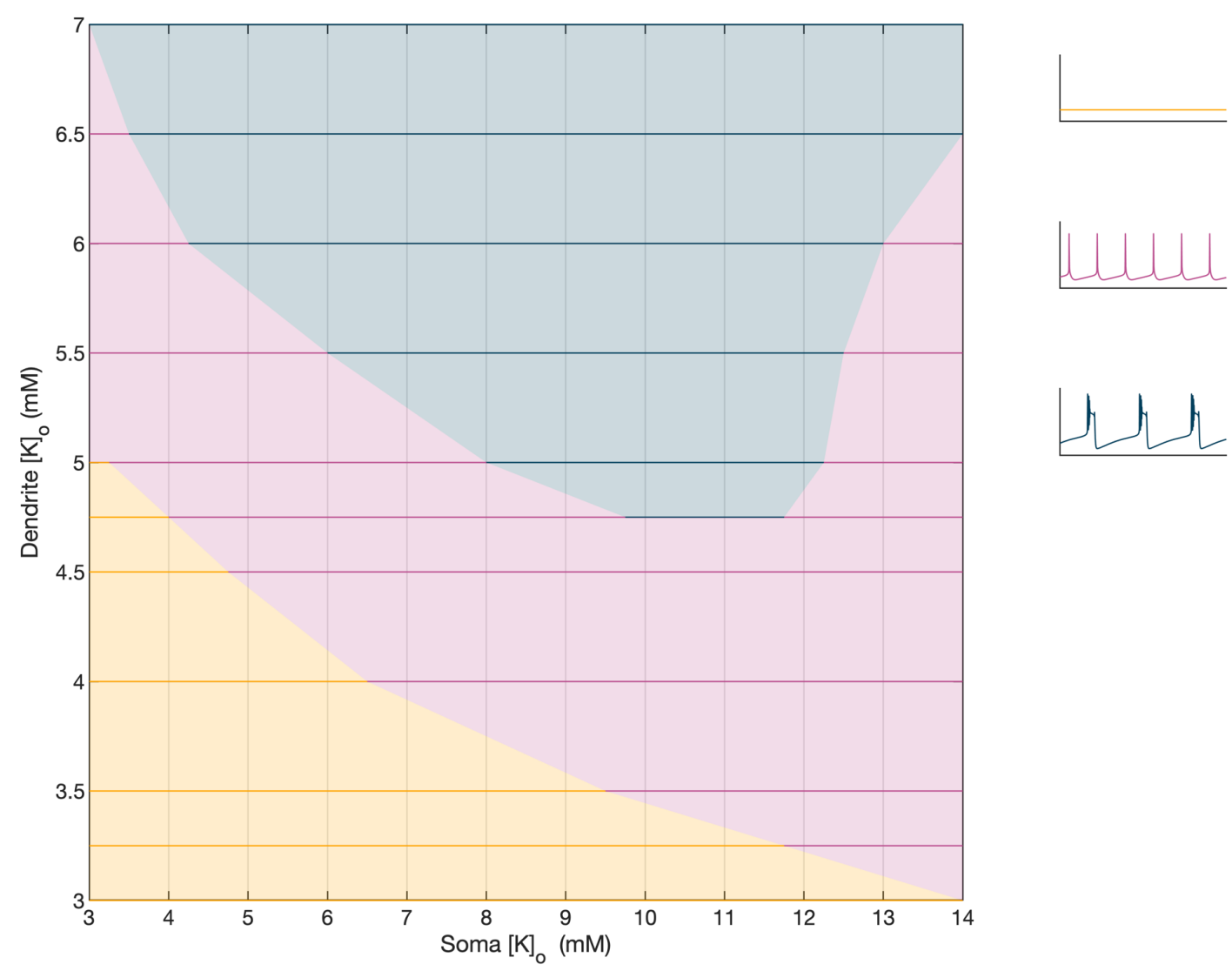

1194 Figure S1. Bifurcation diagram of a single PY cell. The 2D bifurcation diagram demonstrates

1195 the behavior of a single PY cell as a function of extracellular potassium concentration in the 1196 dendritic $\left(\left[\mathrm{K}^{+}\right]_{\mathrm{o} \text {,dend }}\right)$ and somatic compartments $\left(\left[\mathrm{K}^{+}\right]_{\mathrm{o}, \text { soma }}\right)$ used as control parameters. 1197 Concentrations of all other ions were fixed at their reference values, all ion accumulation 1198 mechanisms were blocked and all synaptic connections were removed. The legend on the right 1199 shows the PY cell activity traces for different values of the control parameters: resting (yellow, $1200\left[\mathrm{~K}^{+}\right]_{\mathrm{o}, \text { soma }}=4 \mathrm{mM},\left[\mathrm{K}^{+}\right]_{\mathrm{o}, \text { dend }}=4 \mathrm{mM}$ ), tonic firing (violet, $\left[\mathrm{K}^{+}\right]_{\mathrm{o}, \text { soma }}=4 \mathrm{mM},\left[\mathrm{K}^{+}\right]_{\mathrm{o}, \text { dend }}=6 \mathrm{mM}$ ) 1201 and bursting (dark blue, $\left[\mathrm{K}^{+}\right]_{\mathrm{o}, \text { soma }}=6 \mathrm{mM},\left[\mathrm{K}^{+}\right]_{\mathrm{o} \text {,dend }}=6 \mathrm{mM}$ ). In each panel, 2 seconds of 1202 activity is shown. The colors of the 2D diagram correspond to the types of activity shown in the 
1203 legend. For low $\left[\mathrm{K}^{+}\right]_{\mathrm{o}, \mathrm{dend}}$ and $\left[\mathrm{K}^{+}\right]_{\mathrm{o} \text {,soma }}$ the cell was at rest. A moderate increase in either

$1204\left[\mathrm{~K}^{+}\right]_{\mathrm{o}, \mathrm{dend}}$ or $\left[\mathrm{K}^{+}\right]_{\mathrm{o}, \text { soma, }}$ or both, led to tonic firing. Subsequent increases in these parameters led 1205 to bursting.

A

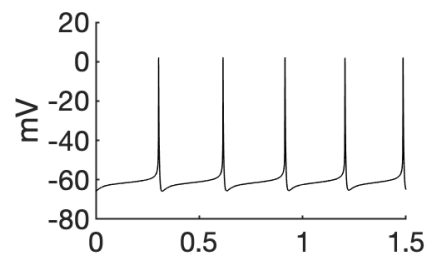

1206

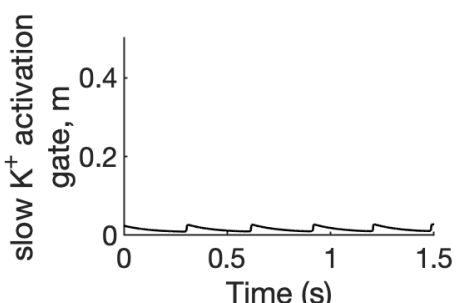

B
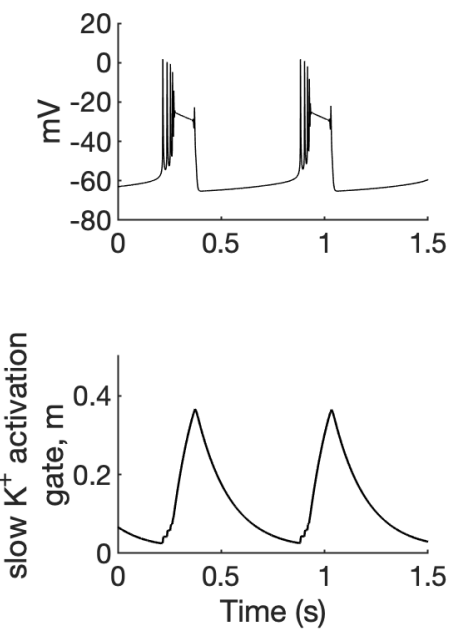

1207 Figure S2. A comparison of tonic firing (A) and bursting (B) of a PY cell. In each column,

1208 the membrane potential of a cell (top) and the activation gate of $I_{K M}$ (bottom) is shown. During

1209 tonic firing, the activation gate of the M-type potassium current was closed. The prolonged

1210 depolarization of the cell during bursting led to the opening of the activation gate $m$ and

1211 activation of the $I_{K M}$ current, which eventually terminated the burst. The simulation was

1212 performed using an isolated PY cell model with the concentrations of all ions fixed at their

1213 reference values, except for $\mathrm{A}:\left[\mathrm{K}^{+}\right]_{\mathrm{o}, \text { soma }}=11 \mathrm{mM},\left[\mathrm{K}^{+}\right]_{\mathrm{o}, \text { dend }}=3.75 \mathrm{mM}, \mathrm{B}:\left[\mathrm{K}^{+}\right]_{\mathrm{o}, \text { soma }}=11 \mathrm{mM}$

1214 and $\left[\mathrm{K}^{+}\right]_{\mathrm{o}, \mathrm{dend}}=5 \mathrm{mM}$. 